CHANGES IN VALUED "CAPACITIES" OF SOILS

AND SEDIMENTS AS INDICATORS OF NONLINEAR

AND TIME-DELAYED ENVIRONMENTAL EFFECTS

William M. Stigliani

International Institute for Applied Systems Analysis

Laxenburg, Austria

RR-88-5

November 1988

Reprinted from Environmental Monitoring and Assessment, volume 10 (1988)

INTERNATIONAL INSTITUTE FOR APPLIED SYSTEMS ANALYSIS

Laxenburg, Austria 
Research Reports, which record research conducted at IIASA, are independently reviewed before publication. However, the views and opinions they express are not necessarily those of the Institute or the National Member Organizations that support it.

Reprinted with permission from Environmental Monitoring and Assessment, 10 (1988), 245-307.

Copyright (C) 1988, Kluwer Academic Publishers.

All rights reserved. No part of this publication may be reproduced or transmitted in any form or by any means, electronic or mechanical, including photocopy, recording, or any information storage or retrieval system, without permission in writing from the copyright holder.

Printed by Novographic, Vienna, Austria 


\section{FOREWORD}

One of the objectives of the International Institute for Applied Systems Analysis (IIASA) Study The Future Environments for Europe: Some Implications of Alternative Development Paths is to characterize nonlinear and time-delayed environmental effects that could be associated with plausible scenarios of Europe's socioeconomic development over the next century. Early warning of such effects is only possible through an understanding of the key mechanisms that serve to regulate the dynamic, broad-scale changes occurring in the environment over time. Indeed, the failure in the past to foresee "sudden" ecological changes, such as forest dieback in central Europe, stems largely from a lack of focus on the key regulators of change.

I believe this paper provides a major contribution to our current understanding of how soils and sediments respond to chemical inputs, and why the response is often manifested as a discontinuous ecological change. The strength of this paper is its treatment of the buffering, sorption, and oxygen-donating capacities of soils and sediments, not as separate entities, but rather, as interlinked properties. It thereby synthesizes ideas that usually have been discussed independently, and demonstrates, in fact, that our understanding of ecological change in soils and sediments is limited unless we also comprehend the full range of interactions between these capacities.

R.E. MUNN

Program Leader

Environment Program 


\title{
CHANGES IN VALUED "CAPACITIES" \\ OF SOILS AND SEDIMENTS AS INDICATORS \\ OF NONLINEAR AND TIME-DELAYED \\ ENVIRONMENTAL EFFECTS
}

\author{
WILLIAM M. STIGLIANI \\ International Institute for Applied Systems Analysis, \\ A-2361 Laxenburg, Austria
}

\begin{abstract}
This paper discusses the buffering, oxygen-donating, and sorption capacities of soils and sediments as an inter-connected system for regulating the retention and release of chemical pollutants. In this context, the author discusses the chemical conditions under which sediments may serve as a source or a sink for toxic materials, and conditions under which soils may retain or release them. It is demonstrated that nonlinear, time-delayed ecological transformations in soils and sediments often can be understood in terms of the interlinked system. The author discusses some possible future long-term environmental problems that might beset Europe, and some implications for a monitoring strategy for foreseeing such problems.

Because the release of adsorbed toxic chemicals from heavily polluted sediments and soils can occur suddenly owing to changes in oxygen status (i.e., redox potential) or acidity, strategies for preventing the long-term release of such materials should not only consider current conditions of $\mathrm{pH}$ and redox potential, but also, how those conditions might change in the future.
\end{abstract}

\section{INTRODUCTION}

Recently, investigators have reported a trend of increasing mercury content in fish in Swedish lakes, even though there has been a significant decrease in mercury emissions from Swedish industries in the last two decades (Hakanson et al., 1988). In commenting on this trend, the authors note that "old Swedish 'sins' are still causing a lot of problems." Lakes in Ontario continue to acidify even though deposition of $\mathrm{SO}_{4}^{-2}$ and $\mathrm{H}^{+}$is decreasing (Dillon et al., 1987). Sudden and unprecedented dieback of forests has occurred in countries such as West Germany, Switzerland, Austria and Czechoslovakia since the early 1980s even though emissions of most major air pollutants in the region have been stable or declining since the mid-1970s (IIASA, 1988).

Such occurrences suggest that: 1) environmental effects may be displaced in time from the activities that cause them; and 2) even when reductions in polluting emissions are enacted, environmental effects may still occur owing to the steady accumulation of polluting materials in the environment over previous decades. Policy makers and the public alike may be surprised by the onset of such recently observed deteriorations in the environment, since prevailing wisdom and common sense might suggest that an era of lowered emissions of polluting 


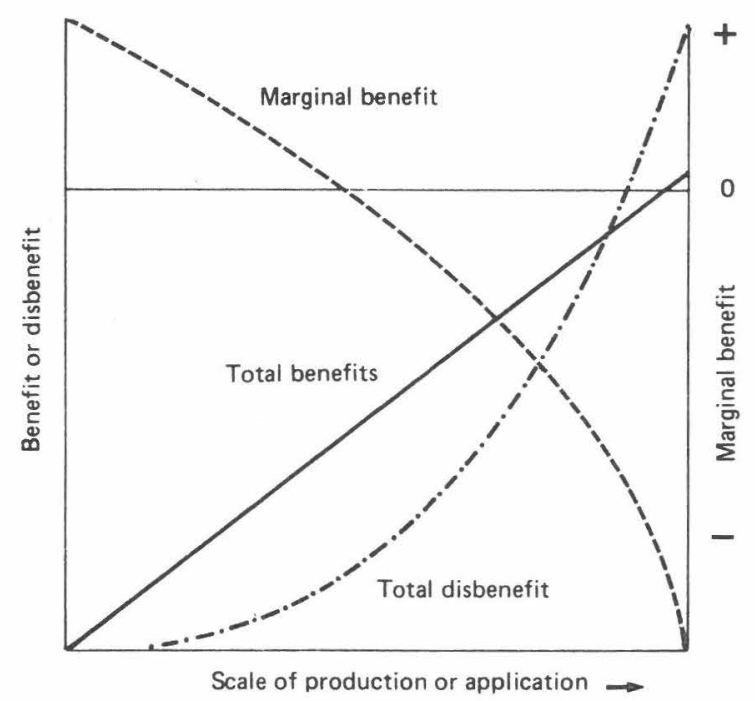

Figure 1 Variation of benefits and disbenefits of a technology with scale of application. The solid curve and the dot-dashed curve show the benefits (linear) and the disbenefits (nonlinear), respectively, while the dashed curve shows the net marginal benefit as a function of scale (essentially the derivative of the difference between the benefit and disbenefit curves). Source Brooks, 1986.

materials to the environment should be accompanied by an improvement in its state, rather than a worsening of it.

As has been indicated by Brooks (1986), industrial societies gain certain socio-economic "benefits" from broad-scale applications of technologies, but such benefits are often accompanied by "disbenefits" to the environment and society as a whole. Brooks further asserts that the manifestation of benefits and disbenefits may be characteristically different in two important respects. Firstly, whereas benefits are usually directly proportional to the scale of application of the technology, disbenefits may vary nonlinearly with scale. (See Figure 1.) Secondly, benefits are typically manifested on "fast" timescales, while disbenefits may become obvious only on relatively "slow" ones. These differences are highly significant because, as noted by Brooks, "a technological activity may become strongly established with influential vested interests during the linear regime, before the disbenefits that increase nonlinearly with scale begin to manifest themselves or become apparent to a wider public."

The purpose of this paper is to explore the aspects of nonlinear ecological behavior and the apparent mismatch of timescales between economic activities and ecological effects. These aspects will be explored from the viewpoint of changes in three important physiochemical "capacities" of soils and sediments; namely, the capacities to buffer acidity, donate oxygen, and adsorb ambient chemical materials. The 
first two capacities are particularly relevant environmental determinants because they are among the most important chemical factors mediating the speciation, solubility, and bioavailability of toxic and ecologically harmful chemicals in the environment. Physical adsorption capacity is also of great environmental significance because it determines the ability of soils and sediments to store or release toxic materials and nutrients.

Each one of these capacities will be described in turn, with examples of how they mediate the environment's response to given anthropogenic chemical inputs. In a later section of this paper, some of the implications of the findings will be described in terms of linkages between specific human activities and nonlinear ecological changes, including a sampler of development-environment interactions that might emerge as important in the future. In addition there is a discussion of how one may design a more robust monitoring system for providing early warning of certain impending environmental changes incorporating historical information and some imaginative speculation about future environmental changes.

The focus of much of the discussion is the European environment, since this paper is in support of an ongoing study at IIASA on the Future Environments for Europe: Some Implications of Alternative Development Paths.

\section{THE SOIL'S CAPACITY FOR BUFFERING AGAINST ACIDIC INPUTS}

An important attribute of many soils is their capacity to neutralize (i.e.; buffer) acids. This capacity plays an essential role in maintaining the stability of fresh water habitats, since soils in the watersheds of lakes serve to stabilize the $\mathrm{pH}$ of the lake waters over a wide range of acidic inputs, thus protecting fish and other aquatic life from large fluctuations in acidity. Soils vary greatly in their ability to neutralize acids. The most poorly buffered soils are those on low-weathering siliceous bedrock, quartzites, sandstones, granites, and felsic gneisses, each of which has a low capacity to replenish alkaline substances lost in acid-neutralization reactions.

\subsection{Historical Perspective}

Over the last 100 to 150 years in many regions of the industrialized countries of North America and Europe, large perturbations of the soils' buffering capacities have occurred, resulting from atmospheric deposition of sulfuric and nitric acids generated during the burning of fossil fuels. Because of the large variability in soil types, even over small spatial scales, the effects on soils and water bodies from acidic atmospheric inputs are not uniform. Nevertheless, regional distinctions can be made. Two representative areas with soils low in buffering 
capacity are the Adirondack Mountains of the United States and Scandinavia. Also described in this paper is the situation in Central Europe. Soils there are generally more resistant to acidification than those in Scandinavia, but because acidic inputs are as much as an order of magnitude higher in Central Europe, its soils are currently even more vulnerable.

A conceptual framework for describing the relative vulnerability of lakes to acidification is illustrated in Figure 2. Watershed soils are grouped according to two fundamental qualities for buffering against atmospheric deposition from sulfuric acid--the ability to retain sulfate, and the ability to supply base cations (NRC 1984). Lakes and streams with watershed soils having both a low ability to retain sulfate inputs and a low ability to release base cations will respond quickly to changes in acid deposition (say on the order of a few years to 20 years). Conversely, lakes and streams associated with watershed soils having very large abilities to retain sulfate and to release base cations may exhibit no response to acidification (on the order of centuries to millenia). Between these two extreme cases are watershed soils having a moderate ability to retain sulfate and/or to release base cations. Such lakes will exhibit a delayed response to acidification (on the order of decades or longer).

Most lakes in North America and Europe are in the "delayed response" category. In order to determine the time of the response of lakes to acidic inputs it is necessary to know the history of emissions upwind from the affected lake, the time trend in lake $\mathrm{pH}$, and the trend in the depletion of the buffering capacity of the soils in the watershed. Unfortunately, there is little precise historical information available in

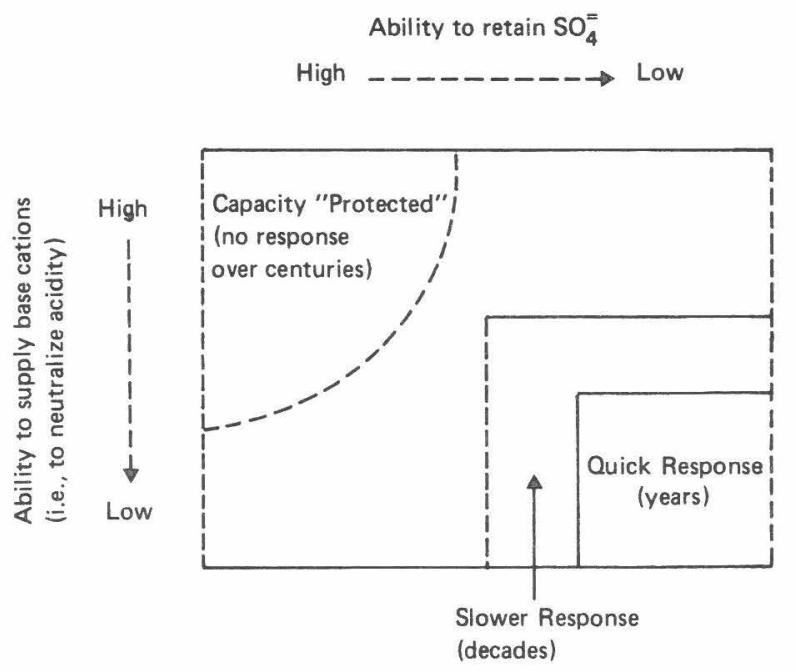

Figure 2 A qualitative presentation of the effect of two major soil properties--the ability to retain sulfate and the ability to supply base cations--on the rate at which streams and lakes respond to changes in acid deposition. Source: NRC, 1984. 
the literature. Big Moose Lake, in the Adirondack Mountains of New York State, is one of the few examples where accurate, simultaneous information exists for trends in $\mathrm{pH}, \mathrm{SO}_{2}$ emissions, and fish populations. (See Figure 3.) One may observe that the $\mathrm{pH}$ of the lake remained essentially constant (except for a slight decline due to natural senescence) over the entire period from 1760 to 1950 . Then, within the space of 30 years (1950 to 1980), the $\mathrm{pH}$ of the lake declined more than one whole $\mathrm{pH}$ unit (corresponding to a factor of 10 increase in acidity). One may notice that the onset of the decline in $\mathrm{pH}$ was not synchronous to the onset of emissions of sulfur. Rather, it occurred 70 years after the beginning of $\mathrm{SO}_{2}$ emissions and 30 years after the emissions had peaked by around 1920. In the 70 years between 1880 and 1950 an estimated 50 grams of sulfur/sq. meter and 2.5 to 3 grams of hydrogen/sq. meter were deposited in the watershed of Big Moose Lake. These quantities were apparently great enough to deplete the sulfate retention and cation release capacities of the soils over this time span. Thus, beginning around 1950 atmospheric acid deposition moved through the buffer-depleted soils and percolated into the lake with little or no neutralization. At that point, acid sensitive fish species such as smallmouth bass, whitefish, and longnose sucker began to disappear, followed in the late 1960 s by the more acid-resistant lake trout.

The history of the acidification of Big Moose Lake clearly demonstrates Brooks' hypothesis of benefits and disbenefits from application of technologies. The benefits of coal burning in the Ohio Valley, upwind from Big Moose Lake, in terms of greatly increased industrial productivity and expanded electric power production exemplifies the "tendency of sociotechnical systems to respond preferentially to 'fast variables' in the environment, as compared to 'slow variables', especially when the latter are less familiar or predictable" (Brooks 1986). In this case the slow variable was the gradual depletion of buffering capacity in the watershed soils. It was not until the $1970 \mathrm{~s}$, nearly 100 years after the advent of coal burning in North America, that the "disbenefits" of coal combustion related to acid deposition became a matter of national concern.

The experience in Europe has been similar to that in the U.S.A. The first area to undergo widespread lake acidification was southern Scandinavia, where many of the watersheds are on igneous bedrock with a very low buffering capacity. Acidification of fresh waters was noticed in southern Norway as early as the 1920s, causing lower yields of salmon in some large rivers. (See Figure 4.) By then, these rivers occasionally showed $\mathrm{pH}$ values below 5.5, and present values are often below 5.0. In Sweden the first biological symptoms of acidification were

\footnotetext{
$1_{\text {This estimate is based on the assumption that the annual wet depositions of sulfur and }}$ hydrogen at Big Moose Lake over the period from 1920 to 1980 were equal to the values for 1980, which were about 1.1 and 0.06 grams/square meter, respectively. Total wet depositions from 1880 to 1920 were assumed to be proportional to emissions.
} 


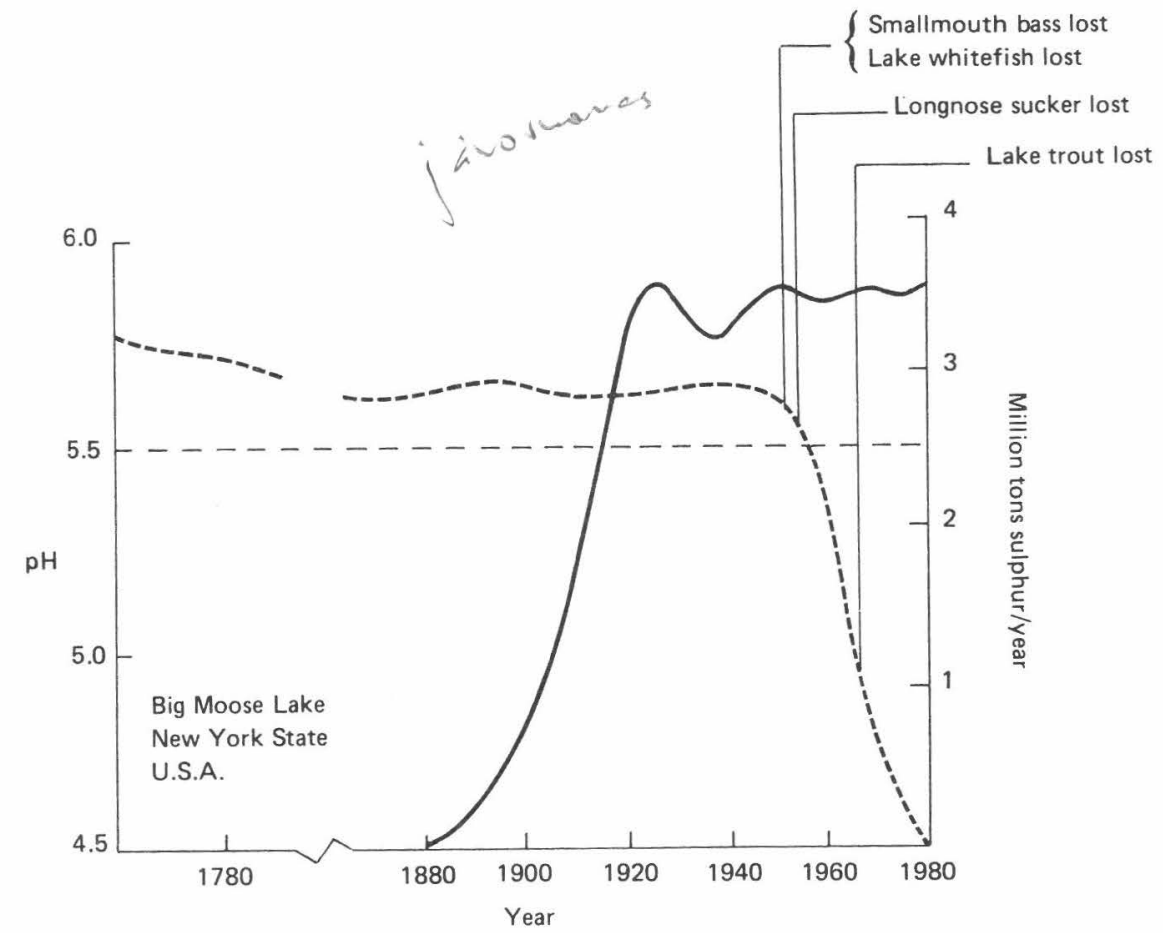

Figure 3 Trends in $\mathrm{pH}$ (dashed curve), emissions of $\mathrm{SO}_{2}$ upwind from the lake (solid curve), and fish extinctions for the period from 1760 to 1980 . The $\mathrm{pH}$ history was reconstructed by analyzing diatom assemblages in sediment core samples (Charles and Norton, 1986). The history of emissions of $\mathrm{SO}_{2}$ upwind from the lake was estimated from data on fuel consumption and sulfur content in coal consumed (Husar, 1986). The history of fish species extinctions was tabulated by Haines, 1986 .

noticed in the 1920 s and 1930 s, with a decrease in number of the most sensitive fish species (roach) in some very poorly buffered lakes with $\mathrm{pH}$ values below 6 during summer. Currently, these lakes are the most acidic in Sweden, with pH values of 4.0 to 4.5 or even less (Almer et al., 1978).

Several historical comparative studies of soil acidification in southern and southwestern Sweden have been conducted recently (Tamm and Hallbaecken, 1988; Andersson, 1986; Tyler et al., 1985). These studies indicate a general trend toward acidification on the order of 0.5 to $0.7 \mathrm{pH}$ units. Tyler et al., in a study of 230 deciduous forests in Skane, the southernmost part of Sweden, concluded that the $\mathrm{pH}$ of the humus layer decreased by about $0.7 \mathrm{pH}$ units since 1949. (See Figure 5). It was further noted (Andersson, 1986) that this decrease corresponds to a change in base saturation of approximately $50 \%$; this means that about half of the sum of the basic cations has been replaced by $H^{+}$and $\mathrm{Al}^{+3}$ over this period. Tamm and Hallbaecken compared changes in soil 


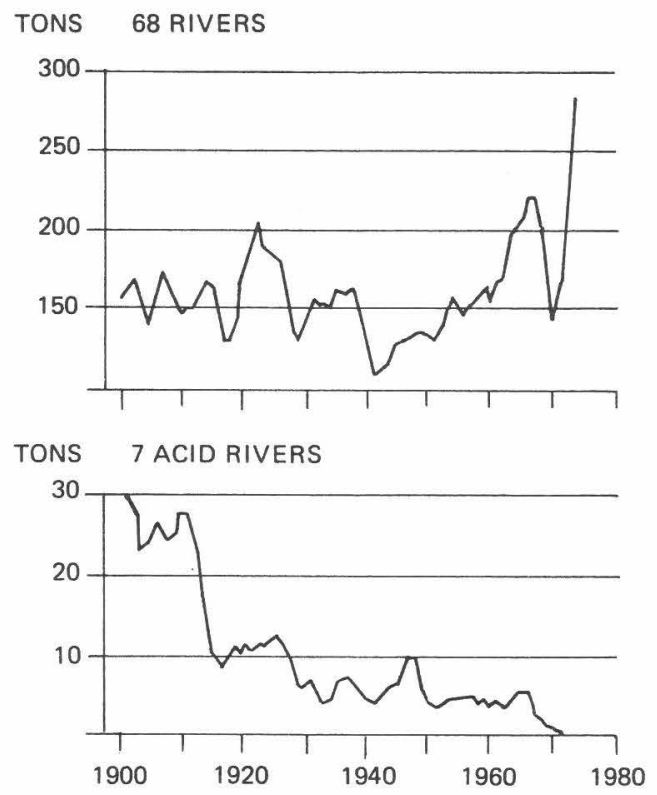

Figure \& Norwegian salmon fishery statistics for 68 unacidified and 7 acidified rivers. Source: Braekke, 1976.

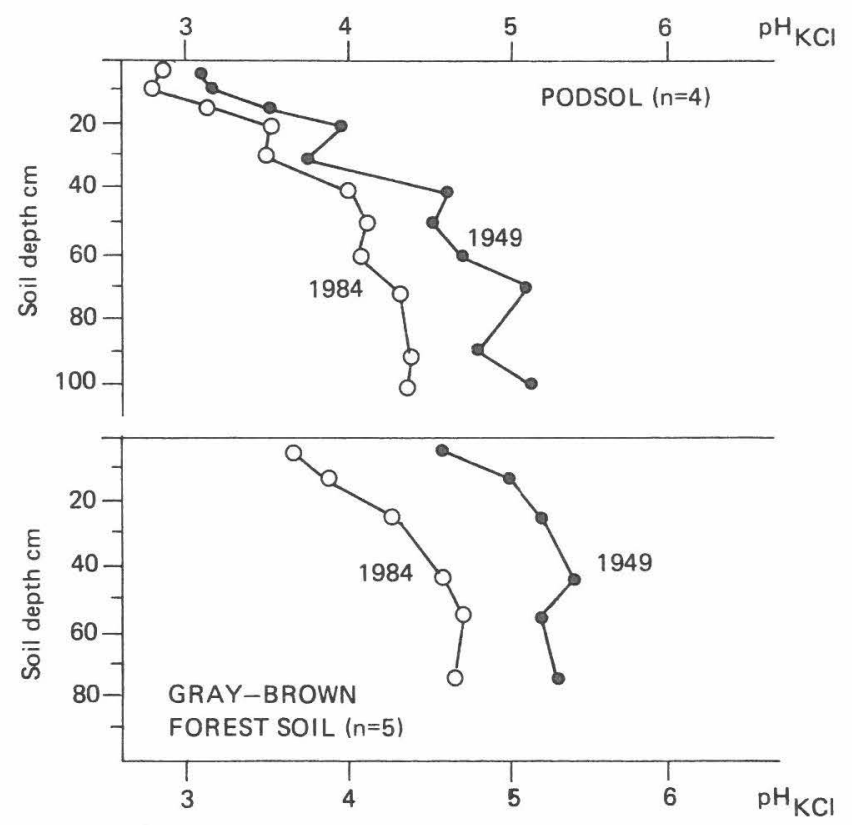

Figure 5 The pH changes at different depths between 1949 and 1984 in forest soils of southernmost Sweden. Source: Tyler et al., 1985. 
acidity since the $1920 \mathrm{~s}$ in two coniferous forests, one in northern Sweden where acid deposition has traditionally been low, and the other in southwestern Sweden receiving relatively high inputs of acid deposition. The authors demonstrated that the $\mathrm{pH}$ of the subsoils ( $\mathrm{B}$ and $\mathrm{C}$ horizons) in the ncrthern forest did not change significantly between 1926 and 1985. However, in the southwestern forest there was a significant trend toward acidification, especially in the $\mathrm{C}$ horizon, (at 70 -cm depth) for which a decrease of 0.5 to $0.7 \mathrm{pH}$ units was calculated between 1927 and $1982-1984 .^{2}$

\subsection{Potential Vulnerabilities in the Future}

In comparison, Central European soils have been more resistant to acidification. Nevertheless, with current sulfur deposition rates as much as ten times higher in Central Europe than are the rates in southern Sweden, ${ }^{3}$ the buffering capacities of many of these soils have reached, or will reach in the coming decades, their limits for neutralizing acids (Alcamo et al. 1987). Figure 6 depicts the percentage of forest soils in the next 50 years in Central Europe that may have a pH less than 4 under various emission scenarios. Soil $\mathrm{pH}$ values near 4 are particularly of concern because of the potential for greatly increased leaching of aluminum and other toxic metals at these acidities. One may observe that even under the current multinational agreement, endorsed by most European countries, for reducing sulfur emissions by $30 \%$ relative to 1980 emissions (effective as of 1993 ), the soils will still be highly vulnerable to acidification. Moreover, deposits of nitric acid from $N O_{x}$ emissions may increase substantially in the future. These emissions will also have to be reduced significantly in order to protect vulnerable soils.

\section{THE SOIL'S CAPACITY TO ADSORB PHOSPHORUS AND TOXIC MATERIALS}

When chemicals are added to soils, either inadvertently or deliberately, their fates are partitioned among four possible pathways. As shown in Figure 7, chemicals (including degradation products) may leach rapidly through the soil into ground and surface waters, they may

\footnotetext{
${ }^{2}$ The authors of the cited papers were well aware of the widely accepted view that the acidity of the upper soil horizons (the humus layer and the bleached horizon of podzol profiles) is strongly affected by the dominating tree species and by the age of the stand. These factors were taken into account in arriving at the final conclusion that acid deposition was the most likely cause of extensive acidification, especially in the deep soil horizons. See cited papers for details.

${ }^{3}$ In some parts of East Germany, Czechoslovakia, and Poland, sulfur deposition levels exceeded $10 \mathrm{grams} / \mathrm{sq}$. meter per year in 1980. Most of southern Scandinavia experienced deposition levels of 1 to 2 grams/sq. meter per year, and a rather small area in the southern extremities experienced levels of 2 to 3 grams/sq. meter per year (Alcamo et al., 1987).
} 


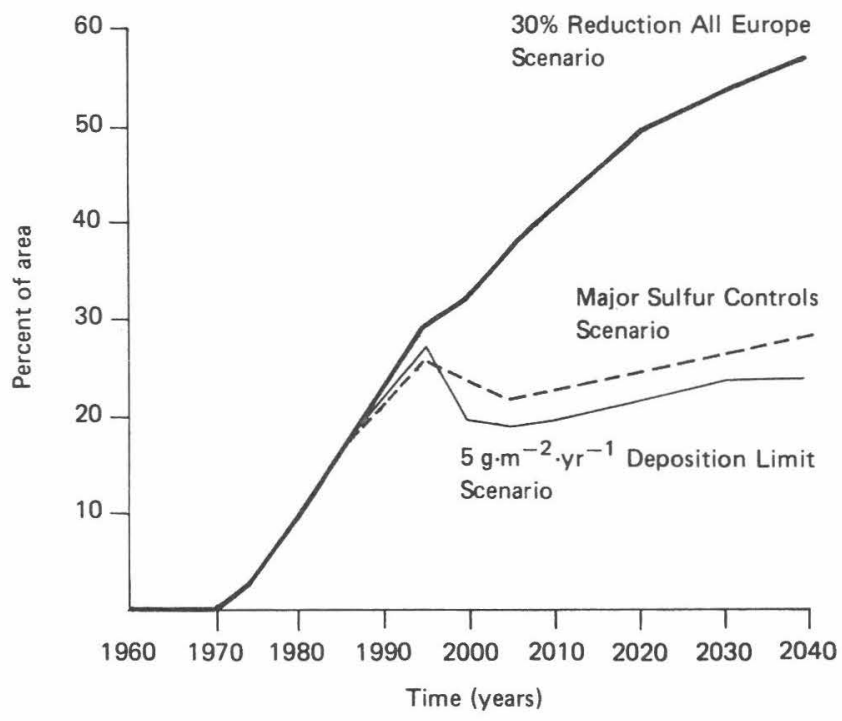

Figure 6 Percentage of Central European forest soils with $\mathrm{pH}$ less than 4.0 for three scenarios. The $30 \%$ Reduction Scenario (relative to 1980 sulfur emissions) is already in effect for most European countries. The Major Sulfur Control Scenario assumes implementation in all European countries of strong pollution control measures including flue gas desulfurization in stationary sources (with $90 \% \mathrm{SO}_{2}$ removal efficiency), and $\mathrm{SO}_{2}$ reduction efficiencies of $50 \%$ in mobile sources. The Deposition Limit Scenario is a cost optimal solution for reducing the maximum deposition level within Europe to 5 $\mathrm{g} / \mathrm{m}^{2} / \mathrm{yr}$. See source for details. Central Europe is defined as East and West Germany, Poland, Czechoslovakia, Hungary, Austria, and Switzerland. Source: Alcamo et al., 1987.

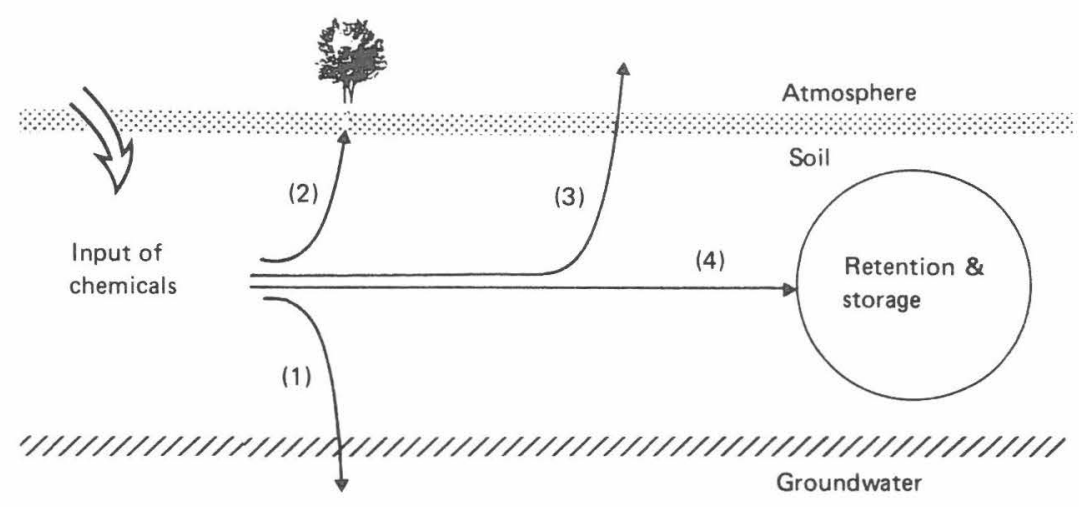

Figure 7 Pathways of chemical inputs to soils. Pathway 1 is rapid leaching through soils into water courses; 2 is uptake by plants; 3 is volatilization to the atmosphere; and 4 is storage and retention in soil. 
be taken up by crops and other vegetation, they may volatilize into the atmosphere, or they may be retained and stored in the soil. For the first three pathways, if the chemicals are deleterious to the environment, observable effects may be noted, often within a short period of time after application. Nitrogen fertilizer is a prime example of an easily leachable chemical that has caused very serious water quality problems in Europe and elsewhere. Regarding pathway 2, the uptake by crops of toxic materials has long been a public health concern, especially in farm areas fertilized by sewage sludge and animal wastes found to be contaminated with such chemicals (Sauerbeck, 1987). Volatile pesticides used in soil fumigation are a widely used class of chemicals following pathway 3. Occasionally, fumigants have caused air quality problems in areas in close proximity to the site of application. (See Huygen and van Ijssel, 1981 for the case of methylbromide.)

It is pathway 4, however, that is of most interest in terms of the potential for nonlinear and time-delayed environmental effects. For as long as the chemical is stored in the soil, it may exhibit little or no ostensible effect. However, the potential danger of chemicals so retained is that they may tend to accumulate, and be released as some threshold is reached for the soil's capacity to hold the chemical. In this section we describe some important chemicals that interact with soils in this way.

\subsection{Phosphorus}

Under natural conditions, phosphorus and nitrogen are normally limiting nutrients in crop production. Beginning in the years shortly after the Second World War, farmers in industrialized countries were able to circumvent this limitation by the application of ever-increasing amounts of phosphorous and synthetically produced nitrogen fertilizers to agricultural soils. As shown in Figure 8, the results in terms of increased productivity were spectacular. However, a heavy price in terms of degradation of the environment has been paid for the increased crop yield. The major cause of this degradation has been the excess quantities of nutrients that have been applied to sustain the yields. In order to ensure that nutrient uptake by crops is maximized, large quantities are typically applied early in the growing season. But uptake is far from complete for either nutrient. Much of the nitrogen is lost to the environment by rapid leaching through the soils into ground and surface waters, and by denitrification to the atmosphere. In contrast, phosphates do not leach rapidly through soils. Rather, a large fraction of the phosphates is adsorbed quite strongly on the surfaces of soil particles, and is thus unavailable for plant uptake.

The effects of nitrogen leaching (in the form of nitrate) into groundwaters have been well documented over the last two decades. (See for example Schroder, 1985.) A less well-known and less studied problem, but one that may prove to be equally as detrimental over the long term, is the potential for saturationn of phosphorus in agricultural soils, and its subsequent leaching into water bodies. Because phos- 


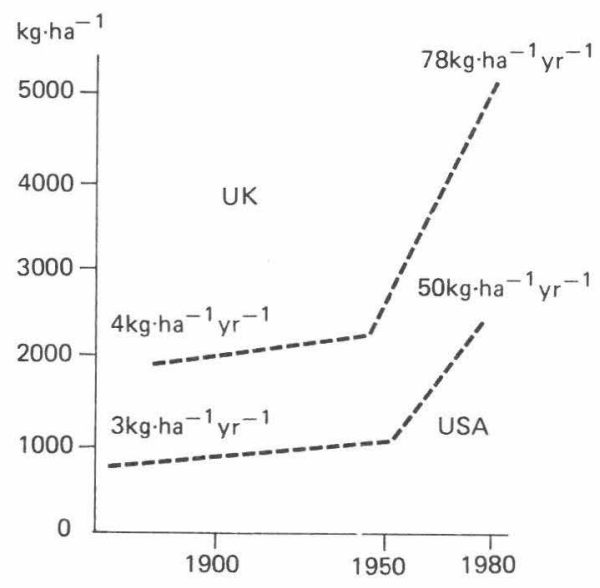

Figure 8 The trends in the yield of wheat in the United States and the United Kingdom over the last 100 years. Numbers refer to increases in yields per year. Trends are generally indicative of crop yields in other industrialized countries as well. Source: FAO data and De Wit, 1981.

phorus is often the limiting nutrient in natural water systems, even small increases of phosphorus inputs may lead to greatly increased rates of eutrophication of lakes, streams, and rivers. In the 1970s, eutrophication caused by the release of phosphorus in domestic sewage, mainly from phosphate additives in detergents, was a well-publicized political issue. Consequently, sewage treatment systems for removing phosphorus evolved quickly. In the case of Sweden and Finland, a phosphorus removal efficiency of over $90 \%$ was achieved by the early 1980s (L. Kauppi, IIASA, personal communication, 1988).

Currently, eutrophication from phosphorus loading is hardly mentioned as a major environmental issue. This general lack of concern may be yet another example whereby the highest priorities for protecting the environment are directed at short-term problems, rather than at those that are only manifested over the long-term. The fact is that agriculture is by far the major consumer of phosphorus in Europe. During the growing season of $1984-1985$ over 3.5 million tons were consumed in fertilizer application. (One may compare this amount to the approximately 0.7 million tons used in detergents.) Moreover, Behrendt (1988) has estimated that approximately $50 \%$ to $60 \%$ of the applied phosphorus is stored in the soils, with the balance absorbed by plant uptake. While generally there is no immediate problem of phosphorus leaching to water courses, over a period of decades accumulation may eventually exhaust the soil's adsorption capacity.

This finite ability of soils to store phosphorus is defined quantitatively by an index called the phosphate sorption capacity (PSC). As shown in Figure 9, the soil may be depicted as a reservoir for phos- 


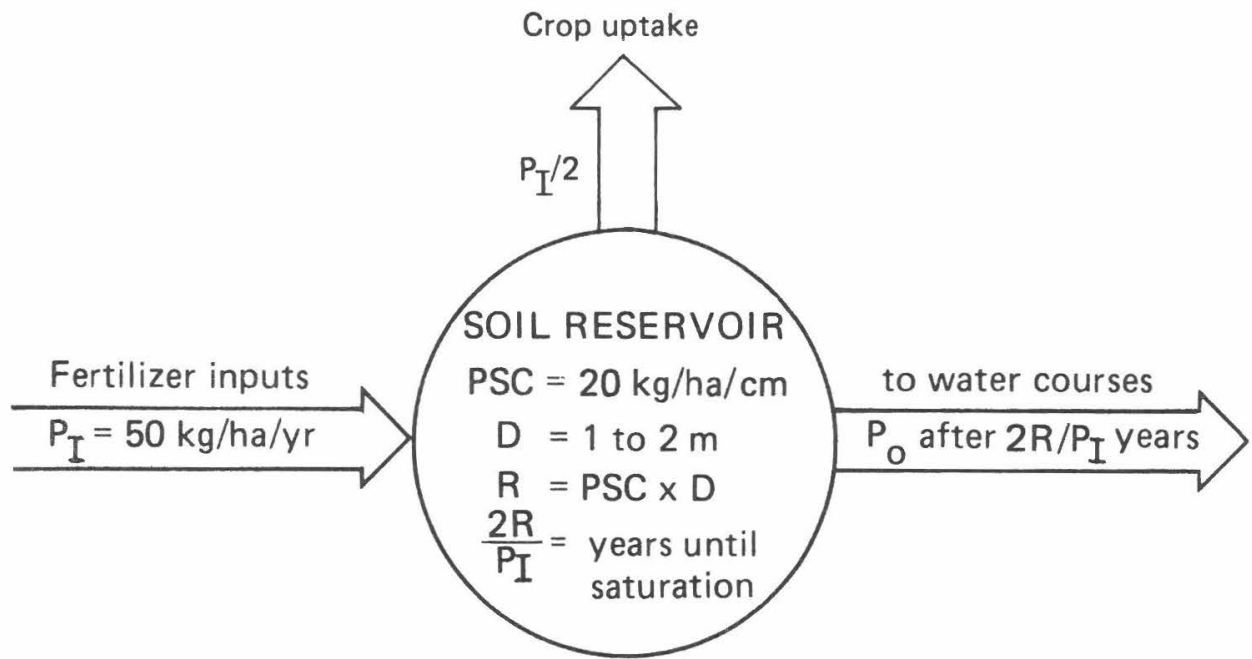

Figure $9 \quad$ Schematic representation of phosphorus inputs/outputs and the time delay until phosphorus leaches from agricultural soils. $P_{I}$ is the phosphorus input; $\mathrm{D}$ is the depth of the water table underneath the soil; $\mathrm{R}$ is the storage capacity of the reservoir; $2 \mathrm{R} / P_{I}$ is the time required for the reservoir to reach saturation assuming that $P_{I}$ remains constant over time and that uptake of phosphorus by crops is one-half of $P_{I} ; P_{0}$ is the phosphorus output. The values assigned to these parameters are representative of many agricultural regions in Europe. Note that for $D$ between 1 and 2 meters, $2 \mathrm{R} / P_{I}$ is 80 to 160 years. Phosphorus has already been accumulating in European soils for approximately 40 years.

phorus inputs. As long as the reservoir is unsaturated, outputs (i.e., leaching of phosphorus from the soil system) are either not observed or minimal. But as soils become saturated with phosphorus, even small inputs may cause significant amounts of phosphate to "leak" from the reservoir. The time delay before effects can be observed is dependent on two factors; the rate of input $\left(P_{I}\right)$, and the size of the reservoir $(\mathrm{R})$. One may observe from this simple model another example of a possible delayed-response, discontinuous environmental change operating over a slow timescale.

In practice, the PSC varies according to soil type and water-table class. There are few precise measurements of PSC, although Dutch investigators have recently calculated values for five sandy soil types in the Netherlands as a function of water-table class (Breeuwsma and Schoumans, 1987). These values ranged from 3.7 to $77 \mathrm{~kg} \mathrm{P} / \mathrm{ha} / \mathrm{cm}$, with a mean value of 22.7 and a median value of $21.6 \mathrm{~kg} \mathrm{P} / \mathrm{ha} / \mathrm{cm}$. Currently, most agricultural soils in Europe are not phosphatesaturated. However, when viewed over a time horizon of decades to a century, and assuming current phosphate application rates, phosphate leaching is a distinct possibility, especially from soils having high inputs, low values of PSC and high water tables. 
A preview of what could be in store for other areas of Europe may be gained by taking note of what is occurring now in probably the most vulnerable area on the continent for phosphate saturation. This is the area of intensive livestock feeding in the Netherlands, where exceedingly high levels of manure, corresponding to average values of phosphorus application on the order of $220-440 \mathrm{~kg}$ phosphorus/ha/ $\mathrm{yr},{ }^{4}$ have been applied to sandy soils at local farms. In these limited areas, extensive phosphorus saturation has already been observed (Breeuwsma and Schoumans, 1987). Figure 10 gives an estimate of the spreading of phosphate saturation in this area given certain application scenarios.

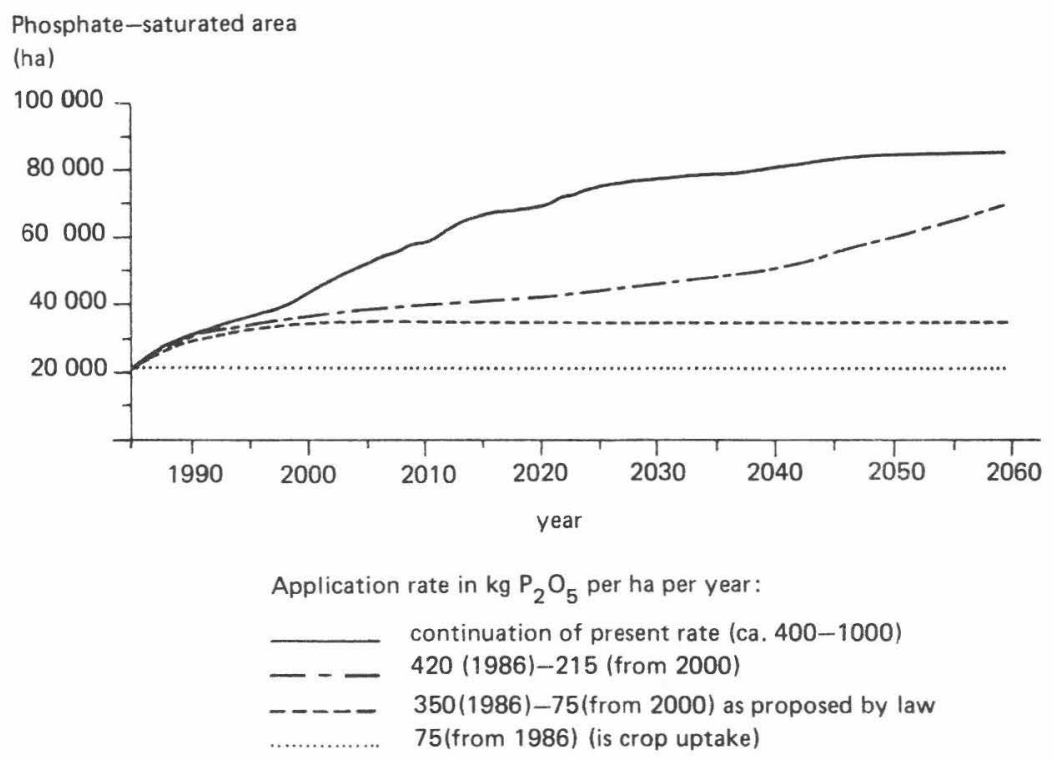

Figure 10 Long-term extension of the area of phosphate-saturated maize land in the Netherlands for four scenarios of phosphate application. Source: Breeuwsma and Schoumans, 1987.

Behrendt (1988) has calculated possible scenarios of phosphate enrichment of agricultural soils in The Netherlands, the Federal Republic of Germany, the German Democratic Republic, and Denmark until the year 2080. Based on national statistics for phosphate use and crop yields, the results may be useful in indicating potential vulnerabilities to future phosphorus leaching. Figure 11 shows the trend of inputs of phosphorus fertilizer, outputs (by crop), and the difference (phosphorus

\footnotetext{
${ }^{4}$ In contrast, the highest levels of phosphorus application in normal agricultural practice in Europe are about $80 \mathrm{~kg} / \mathrm{ha} / \mathrm{yr}$, but more typical application levels are approximately $50 \mathrm{~kg} / \mathrm{ha} /$ year or less.
} 
assumed to be stored in the soil) for agricultural development in the Netherlands from 1945 to 1985. The other countries in the analysis show similar trends, although inputs, outputs and differences are all less than those for Dutch agriculture. One can observe from the Figure that there has been a steadily increasing rate of phosphorus accumulation over the 40 year period. Given a natural content of phosphorus in soils of approximately $1600 \mathrm{~kg} / \mathrm{ha}$, the author estimated that the phosphorus content of soils increased in a range between $40 \%$ (in Denmark) to $85 \%$ (in the Netherlands) during this time. Figure 12 projects these accumulations up to the year 2080, assuming a continuance of current rates of application. The analysis estimates a maximum of a four-fold increase of phosphorus content in Dutch soils and a minimum of twofold increase in Danish soils. Assuming a PSC value of $30 \mathrm{~kg} \mathrm{P} / \mathrm{ha} / \mathrm{cm}$, the calculation shows that the upper one to two meters of soil would be saturated. Based on this analysis, Behrendt estimates that it is possible that more than $10 \%$ of agricultural areas of the investigated countries, specifically those areas with high water tables, low values of PSC, and high application rates of phosphorus, may be vulnerable to phosphate leaching.

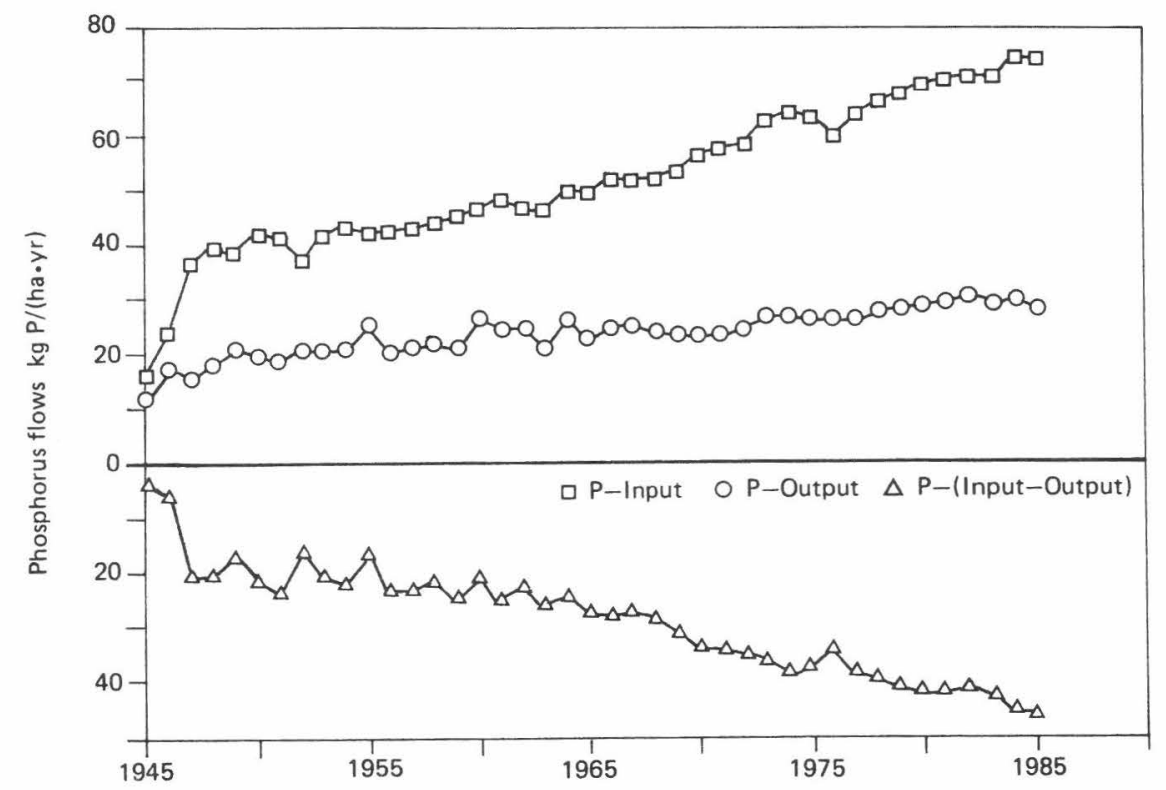

Figure 11 Estimated trends in inputs and outputs for phosphorus use in agriculture in the Netherlands from 1945 to 1985 . P-inputs are for fertilizer and manure application; P-outputs are for phosphorus uptake by plants; P(input-output) is phosphorus stored in the soil. Source: Behrendt, 1988. 


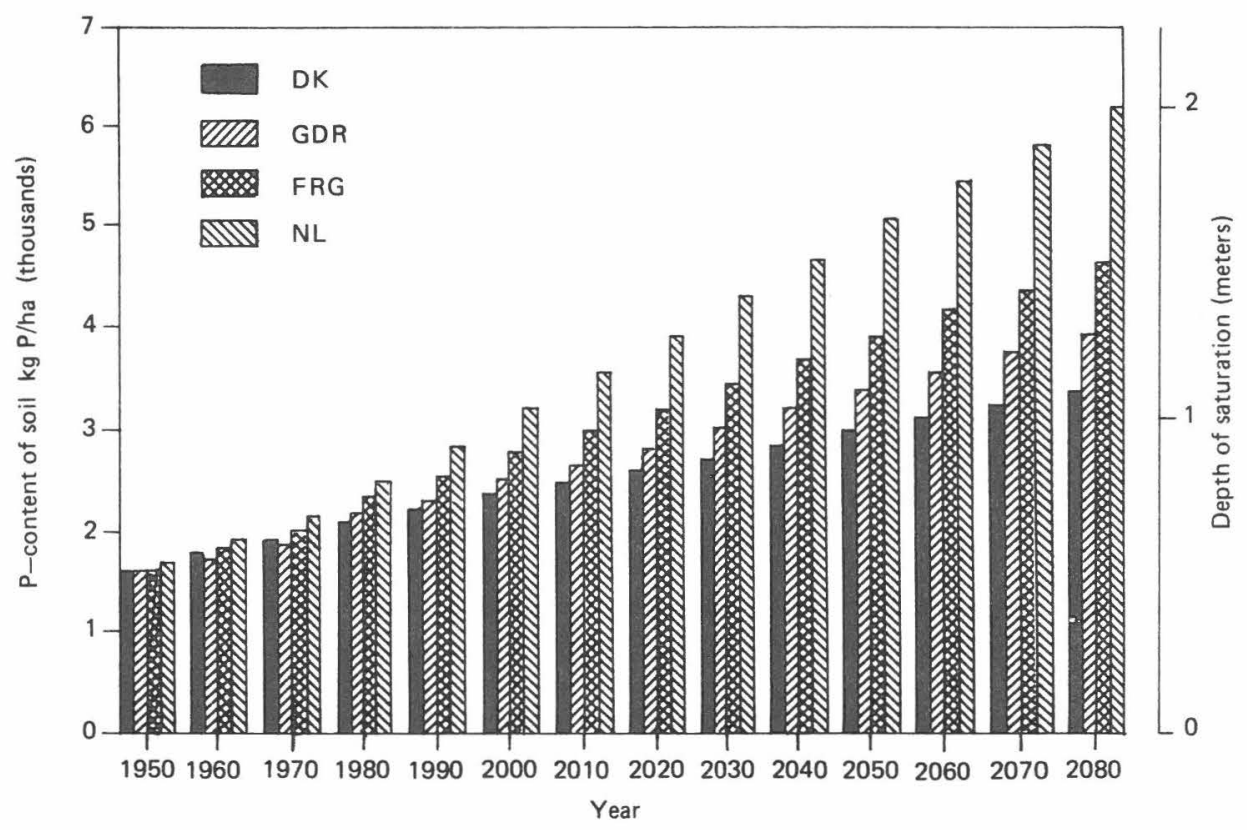

Figure 12 Projected changes of phosphorus content of soils from 1950 to 2080 in Denmark (DK), the German Democratic Republic (GDR), the Federal Republic of Germany (FRG), and the Netherlands (NL). The right-hand scale shows the depth of saturation assuming a PSC of $30 \mathrm{~kg} \mathrm{P} / \mathrm{ha} / \mathrm{cm}$. Estimates were based on the assumption that phosphorus application in future would be the same for the period 1980-1985. Source: Behrendt, 1988.

\subsection{Toxic Materials in Agricultural Soils}

Agricultural soils have been the recipient of large inputs of toxic materials from the addition of pesticides and contaminated fertilizers. (See Sauerbeck, 1987 for a detailed review.) As described previously, some of this material has a rather short life-time in the soil due to leaching, volatilization, or uptake by plants. However, a substantial amount remains stored in the soil. This is especially true of certain heavy metals and organic pesticides that are present in the soils either as insoluble products or as sorbed entities on the surfaces of soil substrates. The mechanisms of retention are complex, depending on soil type, and the physical and chemical conditions in the soil environment.

One of the major properties of soils that contributes to their ability to adsorb and store heavy metals is the presence of cation (i.e., positive ion) exchange sites on their surfaces. Cation exchange may occur when a heavy metal ion exchanges with some other ion that initially occupied an adsorption site on a soil particle. For example, in clay soils heavy metal cations $\left(\mathrm{M}^{+2}\right)$ often exchange with $\mathrm{Ca}^{+2}$ :

$$
\mathrm{M}^{+2}+\text { clay- } \mathrm{Ca} \rightarrow \mathrm{Ca}^{+2}+\text { clay-M }
$$


In addition to heavy metals, certain organic pesticides also tend to accumulate in soils by a similar mechanism. Two examples are diquat and paraquat, each of which has a half-life in soils of at least 10-20 years (de Haan, 1987): As shown in Figure 13 for the case of diquat, such pesticides also contain positive charges and thus may be adsorbed at cation exchange sites.<smiles>C=CC=C(C(=O)[O-])C(=O)O</smiles>

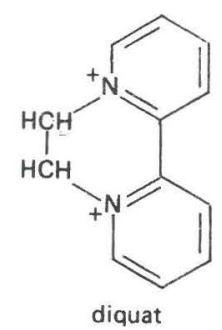

Figure 19 Schematic representation of diquat bonding on soil organic matter. Source: de Haan, 1987, and Stevenson, 1972.

The most important question regarding these stored toxic materials is the potential in the future for increased mobility, resulting in their leaching into groundwaters or uptake by edible plants. In order to make such an assessment, it may be useful to apply the so-called "bottom-up" approach described by Parry and Carter (1987). In this method, one focusses on the potential impact, which in this case is the possible mobilization of toxic materials from agricultural soils, and asks to which factors is the impact most sensitive.

It is well known from the extensive literature on acid deposition, that acidification of soils is associated with the increased mobility of heavy metals. (For example, see Dickson, 1980, and NRC, 1985.) This is true in part because at lower $\mathrm{pHs}$, soil solutions have increased concentrations of $\mathrm{H}^{+}$as well as increases in $\mathrm{Fe}^{+3}$ and $\mathrm{Mn}^{+3}$, which are more soluble under acidic conditions. These cations compete with toxic heavy metals (and possibly with organic pesticides such as diquat) for cation exchange sites, rendering the toxic materials to be less adsorbed and thus more mobile. An additional factor is that at higher $\mathrm{pHs}$, the insoluble oxides of iron and manganese tend to adsorb toxic materials on their surfaces. As the oxides become soluble at lower pHs,adsorption no longer pertains, resulting in the release of the toxic components.

The important point for the subject of this paper, however, can be observed in Figure 14. Laboratory experiments have shown that the percent of heavy metal cation adsorbed to soil components undergoes an abrupt change over a narrow $\mathrm{pH}$ range. Table 1 presents values of $\mathrm{pH}_{50}$ (the $\mathrm{pH}$ at which $50 \%$ of the original cation concentration is adsorbed) for various heavy metals on two different soil substrates.

Heavy metals commonly found in European agricultural soils include cadmium, chromium, copper, mercury, nickel, lead, and zinc (Sauerbeck, 1987). Of these, cadmium, copper, nickel and zinc are most readily mobilized under acidic conditions. Cadmium has been one 


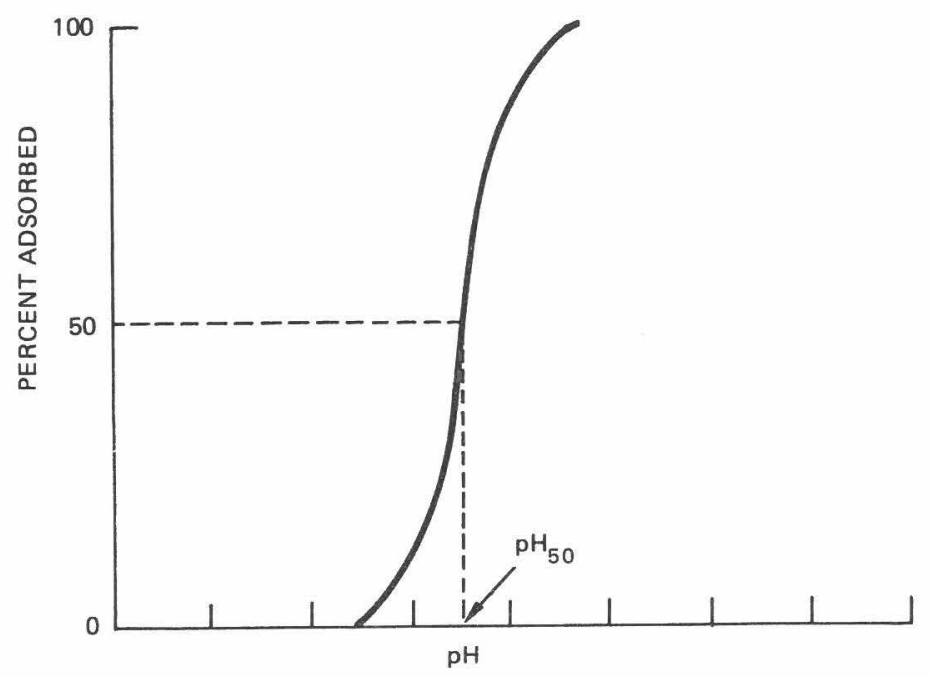

Figure 14 Typical pH adsorption curve for divalent cations on hydrous metal oxides $\left(p H_{50}\right.$ values may range from about 3 to 8$)$. Source: NRC, 1985.

Table 1. Adsorption of Trace Heavy Metals on Colloidal Metal Hydroxides

\begin{tabular}{|c|c|c|c|c|c|c|c|c|c|}
\hline $\begin{array}{c}\mathrm{Fe}(\mathrm{OH})_{3} \mathrm{gel}^{a} \\
\text { metal }^{b}: \\
\mathrm{pH}_{50}:\end{array}$ & $\begin{array}{l}\mathrm{Pb} \\
3.0\end{array}$ & $<$ & $\begin{array}{l}\mathrm{Cu} \\
\mathbf{4 . 3}\end{array}$ & $<$ & $\begin{array}{l}\mathrm{Zn} \\
5.3\end{array}$ & $<$ & $\begin{array}{l}\mathrm{Ni} \\
5.7\end{array}$ & $<$ & $\begin{array}{l}\mathrm{Cd} \\
5.9\end{array}$ \\
\hline $\begin{array}{c}\mathrm{Al}(\mathrm{OH})_{3} \text { gel } \\
\text { metal: } \\
\mathrm{pH}_{50}:\end{array}$ & $\begin{array}{l}\mathrm{Cu} \\
4.8\end{array}$ & $<$ & $\begin{array}{l}\mathrm{Pb} \\
5.2\end{array}$ & $<$ & $\begin{array}{l}\mathrm{Zn} \\
5.6\end{array}$ & $<$ & $\begin{array}{l}\mathrm{Ni} \\
6.3\end{array}$ & $<$ & $\begin{array}{l}\mathrm{Cd} \\
6.6 \\
\end{array}$ \\
\hline
\end{tabular}

a) Gel concentration: $9.3 \times 10^{-2} \mathrm{M} \mathrm{Al}$ or Fe

${ }^{b}$ Trace metal concentration: $1.25 \times 10^{-4} \mathrm{M}$

Source: NRC, 1985.

of the most thoroughly studied heavy metals because of its high toxicity and high biological activity. Large quantities have inadvertently been added to agricultural soils because it occurs as an impurity in phosphate fertilizers, ranging from $5 \mathrm{ppm}$ to $300 \mathrm{ppm}$ depending on the source of fertilizer (Henkens, 1983). In addition, other major sources of cadmium pollution include incineration of domestic and commercial wastes, application of sewage sludge to agricultural areas, combustion of fossil fuels, zinc smelting, and effluent wastes from various industrial activities. Olsthoorn and Thomas (1986) have estimated that accumulations of cadmium in Dutch soils from all sources could cause a doubling of cadmium content (to $0.6 \mathrm{ppm}$ ) by the year $2060 .^{5}$ Foerstner

\footnotetext{
${ }^{5}$ In the Netherlands soils containing greater than $1 \mathrm{ppm}$ of cadmium are assumed to be contaminated.
} 
(1986) estimated a possible increase of cadmium levels to a critical 3 ppm in some Swiss soils within the next 20-30 years, if the current practice of composting cadmium-contaminated wastes is continued.

\subsection{Potential Vulnerabilities in the Future}

Having established acidification as a major determinant of the mobility of toxic materials in contaminated soils, it is necessary to review the possibilities in the future for broad-scale changes in the acid status of agricultural soils. On a regional scale, the most important source of acidity in non-agricultural soils has been acid deposition from the combustion of fossil fuels. We have seen in the previous section that the forest soils of Central Europe are severely threatened by further acidification. On a more local scale, major sources have been acid drainage from coal mining activities (Brugam and Lusk, 1986), and drainage, for agricultural purposes, of wetlands containing large deposits of reduced sulfur minerals (Renberg, 1986).

In agricultural soils, in addition to acid deposition, high inputs of nitrogen fertilizer and removal of crops are major sources of acidification (De Vries and Breeuwsma, 1986). Addition of fertilizers containing ammonium results in a net production of $\mathrm{H}^{+}$in soils after nitrification and plant uptake; crop removal results in a net loss of base cations from the soils, thus decreasing its acid neutralizing capacity. However, agricultural soils have been protected from acidification due to the routine practice of liming, which helps to maintain the soil's structural stability and raises the soil's $\mathrm{pH}$ to values near 6.0. Indeed, experiments have already demonstrated the effectiveness of decreasing the bioavailability of cadmium by raising the $\mathrm{pH}$ of agricultural soils. John et al. (1972) and Miller et al. (1976) found that decreasing soil pH was associated with increasing concentrations of cadmium in radish, lettuce, and soybeans. Williams and David (1976) amended a soil $[\mathrm{pH}$ $=5.4,<1 \mu g \mathrm{Cd} / \mathrm{g}$ soil $\left(1 \mathrm{~N} \mathrm{HCl}\right.$ extraction)] with $\mathrm{CaSO}_{4}$ to $\mathrm{pH} 5.1$ and with $\mathrm{CaCO}_{3}$ or $\mathrm{MgCO}_{3}$ to $\mathrm{pH} 6.0$ and 6.8. They observed that the uptake of cadmium by subterranean clover increased when the $\mathrm{pH}$ was lowered and decreased when the $\mathrm{pH}$ was raised. Working with a soil amended with cadmium at varying rates (0 to $100 \mu g \mathrm{Cd} / \mathrm{g}$ dry soil) , John (1972) found that an application of lime $\left(\mathrm{Ca}(\mathrm{OH})_{2}\right)$ which increased the $\mathrm{pH}$ of the soil from 4.1 to 5.5 resulted in decreased cadmium concentrations in radish tops and roots. Other investigators (Williams and David, 1973; MacLean, 1976; Wallace et al., 1977) have observed decreased cadmium uptake by subterranean clover, lettuce, and corn with additions of lime or $\mathrm{CaCO}_{3}$ to the soil.

Perhaps a new source of soil acidification in Europe may occur if current plans to cut back agricultural production, for example in the EC countries, are enacted. The agricultural sector in most of the countries in the EC is overproducing by approximately $20 \%$. Serious discussions are currently underway to reduce, by a large fraction, the areas currently engaged in agricultural activities. One result may be the 
"abandoning" of farm land on a very large scale, perhaps $20 \%$ or more. If these lands are no longer limed, there may be a large and rapid increase in acidity. While limed soils are maintained at $\mathrm{pHs}$ of about 6 , upon the cessation of liming the $\mathrm{pH}$ could typically decrease to about 5 for clay soils, and about $4-4.5$ for sandy soils (W. de Vries, Soil Survey Institute, Wageningen, The Netherlands, personal communication, 1988). This change could be followed subsequently by leaching of toxic materials from the abandoned soils.

On the other hand, recent public concern about the issue of toxic chemicals in aquatic and agricultural systems has resulted in more stringent laws within the EC and elsewhere in Europe, which may well reduce the levels of toxic materials flowing through the European environment. Such laws often set standards of maximum permissible limits for toxic materials in soils, foods, or water bodies. However, as described in the previous discussion, the underlying physical and chemical conditions of the soil are the most important factors determining the mobility of toxic materials in the environment. Thus, setting standards alone without consideration of the physical and chemical factors may not be enough to ensure that safe levels of toxic materials are maintained in the future.

In our previous discussion about sorption capacities, we stated that the ability of soils to store chemicals depends on the rate of input of the chemical and on the size of the reservoir. (See Figure 9.) In the case of abandoned lands, even though inputs of toxic materials will presumably cease, or at least be greatly reduced, materials stored from previous inputs may be released due to a rapid shrinking of the size of the reservoir. This is shown schematically in Figure 15. The effect may be aggravated if the least productive lands (the so-called "marginal" lands) are taken out of production, since these may have experienced the largest inputs of cadmium (via phosphate fertilization) and pesticides. Not much has been written about the environmental implications of abandoning agricultural land, and this topic merits extensive research.

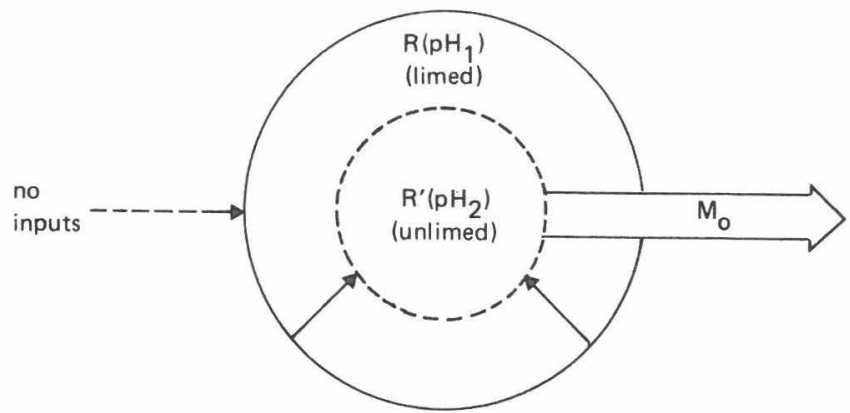

Figure 15 Schematic representation of the effect of decreasing $\mathrm{pH}$ on the size of the reservoir for storage of toxic materials. $\mathrm{R}\left(p H_{1}\right)$ is the storage capacity at $p H_{1}$, which is about 6.0 in limed soils. $\mathbf{R}^{\prime}\left(\mathrm{pH}_{2}\right)$ is the reduced storage capacity at $\mathrm{pH}_{2}$, which is more acidic in absence of liming. 


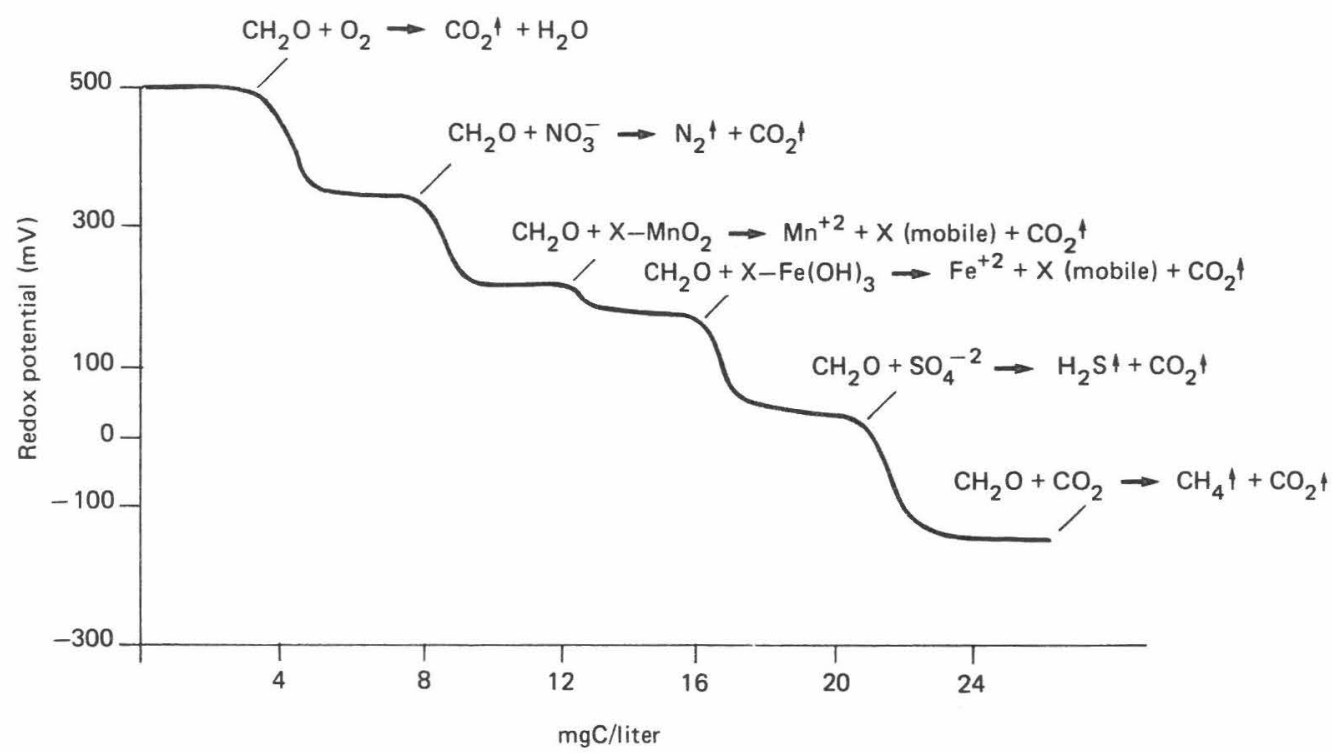

Figure 16 Schematic illustration of the order in which microorganisms select oxygenbearing molecules for oxidation of organic carbon to $\mathrm{CO}_{2}$ in $\mathrm{O}_{2}$-deficient environments. $\mathrm{O}_{2}$ in natural waters is sufficient to oxidize about $4 \mathrm{mg}$ of organic carbon $\left(\mathrm{CH}_{2} \mathrm{O}\right)$ per liter of water. When $\mathrm{O}_{2}$ is not replenished from the atmosphere, the oxygen will be extracted from other molecules in the order shown. See Table 2 for more detailed descriptions.

\section{OXYGEN DONATING CAPACITIES OF SOILS AND SEDIMENTS}

One of the fundamental requirements of life is the need to generate biochemical energy attained through the oxidation of organic carbon to $\mathrm{CO}_{2}$. The most efficient energy-producing mechanism is that of respiration by which molecular oxygen $\left(\mathrm{O}_{2}\right)$ is the oxidizing agent. While the atmosphere clearly possesses the most abundant source of $\mathrm{O}_{2}$, it is not a particularly reactive medium for oxidation reactions. (This is fortuitous, for otherwise we would burn to death.) This is true because of the relatively low concentrations of chemical compounds (mostly free radicals) that are reactive enough to overcome the high energy needed for breaking the oxygen-oxygen bond of $\mathrm{O}_{2}$. The opposite situation applies to oxidation reactions in soils, waters, and bottom sediments. Here there are plentiful microorganisms capable of utilizing $\mathrm{O}_{2}$ in respiration, but such reactions are restricted by the relatively low solubility of $\mathrm{O}_{2}$. However, the earth's aquatic and terrestrial ecosystems contain abundant populations of microorganisms capable of utilizing oxygen from other oxygen-containing compounds. Generally, soils are more reactive than water systems. They may possess a greater capacity than waters for the absorption of $O_{2}$, and they support even greater 
populations of microorganisms that obtain energy through respiration, or through oxidation reactions utilizing oxygen from other oxygenbearing molecules.

Because soils, waters, and sediments are all ultimately limited with respect to the availability of $\mathrm{O}_{2}$, invariably microorganisms appropriate the required oxygen from oxygen-bearing molecules. The following chemical sources are utilized ubiquitously in the biosphere: nitrate $\left(\mathrm{NO}_{3}^{-}\right)$, manganese and iron oxides $\left(\mathrm{Mn}_{2} \mathrm{O}_{3}, \mathrm{Fe}_{2} \mathrm{O}_{3}\right)$, sulfate $\left(\mathrm{SO}_{4}^{-2}\right)$, and carbon dioxide $\left(\mathrm{CO}_{2}\right)$. However, as shown schematically in Figure 16, the extraction of oxygen from these compounds proceeds via a preordained ordering, rather than by random utilization of all available oxygen. This ordering results from the relative oxidation efficiencies of each molecule, or, in chemical terms, their "redox" potential. (When an oxygen atom is extracted, the compound donating the oxygen is "reduced", and the compound receiving the oxygen is "oxidized", hence the term "redox".) One can think of the redox potential as a kind of "chemical switch" mechanism, determining the observed sequence by which these chemicals are utilized by microorganisms.

Moreover, as described in Table 2 and elaborated upon in the following discussion, each of the redox reactions is associated with characteristic chemical by-products that may affect the environment in different ways. Sudden changes in the redox potential are possible, which may lead to deleterious environmental effects that appear as sudden, and often unpredictable, occurrences. Some examples of how this behavior may create serious environmental problems are described in the following discussion.

\subsection{Anoxia in Coastal Waters}

Anoxia may occur in intermediate or deep waters of a gulf or a fjord with restricted circulation with surface waters (R. Wollast, Free University of Brussels, personal communication, 1987). Figure 17 illustrates the underlying mechanism. As carbon is gradually added to the deeper waters, $\mathrm{O}_{2}$ is progressively consumed by aerobic bacterial activity, and since there is little mixing with the surface layers, replenishment of $\mathrm{O}_{2}$ from the atmosphere does not occur. (The oxygen present in one liter of sea-water is sufficient to oxidize approximately 4 $\mathrm{mg}$ of organic carbon.) When the amount of organic carbon exceeds 4 $\mathrm{mg} / \mathrm{l}$, a sudden drop of redox potential occurs. Because sea water is rich in sulfate salts relative to other oxygen-containing compounds, the favored reaction is sulfate reduction to hydrogen sulfide $\left(\mathrm{H}_{2} \mathrm{~S}\right)$, a chemical that is extremely toxic to fish and humans. Although $\mathrm{H}_{2} \mathrm{~S}$ is generally confined to the lower layers of sea water, during a storm event there may be rapid mixing of the deeper, anoxic layers with the surface layer, resulting in massive fish kills from exposure to $\mathrm{H}_{2} \mathrm{~S}$.

As shown in Figure 18, in coastal areas of Denmark in 1981 and again in 1983, there were unprecedented depletions of oxygen and 
Table 2.

REDOX REACTION

$$
\text { 1. } \begin{aligned}
& \mathrm{O}_{2}+\mathrm{CH}_{2} \mathrm{O} \\
& \rightarrow \mathrm{CO}_{2}+\mathrm{H}_{2} \mathrm{O}
\end{aligned}
$$

$$
\text { 2. } \begin{aligned}
(4 / 5) \mathrm{NO}_{3}^{-}+\mathrm{CH}_{2} \mathrm{O} \\
+(4 / 5) \mathrm{H}^{+} \rightarrow \mathrm{CO}_{2} \\
+(2 / 5) \mathrm{N}_{2}+(7 / 5) \mathrm{H}_{2} \mathrm{O}
\end{aligned}
$$

3a. $2 \mathrm{MnO}_{2}+\mathrm{CH}_{2} \mathrm{O}+4 \mathrm{H}^{+}$ $\rightarrow 2 \mathrm{Mn}^{+2}+3 \mathrm{H}_{2} \mathrm{O}+\mathrm{CO}_{2}$

3b. $4 \mathrm{Fe}(\mathrm{OH})_{3}+\mathrm{CH}_{2} \mathrm{O}+8 \mathrm{H}^{+}$ $\rightarrow 4 \mathrm{Fe}^{+2}+11 \mathrm{H}_{2} \mathrm{O}+\mathrm{CO}_{2}$

4a. $(1 / 2) \mathrm{SO}_{4}^{-2}+\mathrm{CH}_{2} \mathrm{O}$ $+\mathrm{H}^{+} \rightarrow(1 / 2) \mathrm{H}_{2} \mathrm{~S}+\mathrm{H}_{2} \mathrm{O}$ $+\mathrm{CO}_{2}$

\section{REACTION PRODUCTS/CONSEQUENCES}

The aerobic condition, characterized by the highest redox potential, occurring when there is an abundance of $\mathrm{O}_{2}$, and the relative absence of organic matter owing to oxic decomposition by aerobic microorganisms prior to burial. Two examples are the aerobic digestion of sewage wastes, and the decomposition of organic matter near the surface of well aerated soils. The end products, $\mathrm{CO}_{2}$ and water, are typically benign.

When molecular oxygen is depleted from the soil, as would be the case, for example, in water-logged soils, available nitrate is the most efficient source of oxygen. Denitrifying bacteria extract oxygen and release $\mathrm{N}_{2}$ and $\mathrm{N}_{2} \mathrm{O}$. In agricultural soils, this process can lead to losses of nitrogen fertilizer amounting to as much as 20\% of inputs (Behrendt, 1988). Denitrifying bacteria are also very active in heavily polluted rivers having long residence times, or in stratified estuaries where organic matter accumulates. In some estuary systems denitrification may significantly affect the transfer of nitrogen to the adjacent coastal waters and to the atmosphere.

In anaerobic environments in which nitrates are in low concentration and manganese and ferric oxides are abundant, the metal oxides may be a source for microbial oxidation. This may be the case in natural soils, and in the sediments of lakes and rivers. The environmental significance of these metal oxides is that they serve a dual role. Not only are they a source of oxygen to microorganisms, but also, they are important for their capacity to bond toxic heavy metals, deleterious organic compounds, phosphates, and gases. When the metal oxides are reduced, they become water-soluble, and lose their bonding ability. This loss may result in the release of toxic materials.

Sulfidic conditions are brought about almost entirely by the bacterial reduction of sulfate to $\mathrm{H}_{2} \mathrm{~S}$ and $H S^{-}$accompanying organic matter decomposition. Sulfate reduction is very common in marine sediments because of the ubiquity of organic matter and the abundance of dissolved sulfate in sea water. Such reactions are also important in areas affected by acidic deposition in the form of sulfuric acid. $\mathrm{H}_{2} \mathrm{~S}$ is an extremely toxic gas. Sulfides are also important in scavenging heavy metals in bottom sediments. 
4b. $\mathrm{MeS}_{2}+(7 / 2) \mathrm{O}_{2}+\mathrm{H}_{2} \mathrm{O}$ $\rightarrow \mathrm{Me}^{+2}+2 \mathrm{SO}_{4}^{-2}+2 \mathrm{H}^{+}$
5. (1/2) $\mathrm{CO}_{2}+\mathrm{CH}_{2} \mathrm{O}$ $\rightarrow(1 / 2) \mathrm{CH}_{4}+\mathrm{CO}_{2}$
The reverse reaction, in which a heavy-metal sulfide $\left(M e S_{2}\right)$ is converted to sulfate may also occur when anaerobic sediments are exposed to the atmosphere, as in the case of the raising of dredge spoils. It may also occur when wetlands containing pyrites $\left(\mathrm{FeS}_{2}\right)$ are drained for agriculture, or in coal mining areas as acid mine drainage. One consequence may be an increase in acidification from the generation of sulfuric acid; another might be the release of toxic metals.

\begin{abstract}
Under anaerobic conditions at a redox potential of less than $-200 \mathrm{mV}$ and in the presence of specialized bacteria as may be found in swamps, flooded areas, rice paddies, and the sediments of enclosed bays and lakes, oxygen may be extracted from $\mathrm{CO}_{2}$ with the emission of methane. This reaction is more typical in freshwater systems because sulfate concentrations are much lower than in marine environments, averaging about one-hundredth the concentration in seawater. Methane is a critical gas in the determination of global climate. Since the early 1970 s, global atmospheric methane levels have been increasing at a rate of $1 \%$ per year. Although the reasons for this increase are still under investigation, the expansion of rice paddy cultivation in southeast Asia has been cited as one of the likely causes (Crutzen and Graedel, 1986).
\end{abstract}

releases of hydrogen sulfide, causing the killing of large numbers of fish. The Danish National Agency for Environmental Protection concluded, in a comprehensive investigation, that meteorological conditions had triggered the two episodes, but that the underlying cause was the increasing over-fertilization of the coastal waters with an accompanying over-abundance of oxidizable organic carbon. The source of nutrient inputs was primarily nitrogen from agricultural activities (Schroder, 1985). This same phenomenon has been observed in the Gulf of Saronik near Athens. The cause in this case is not nutrient run-off from agricultural activities, but the direct disposal of sewage, again containing large concentrations of oxidizable organic carbon, from the city of Athens (R. Wollast, Free University of Brussels, personal communication, 1987).

\subsection{The Impact of Dredging Sediments in Coastal Areas}

\subsubsection{Magnitude of the Problem}

For nautical reasons, dredging of sediments in rivers, estuaries, and coastal areas, and subsequent aquatic or upland disposal of the dredge spoils are routine activities carried out all over the world. However, in the process of raising, transporting, and disposing of the sediments to 


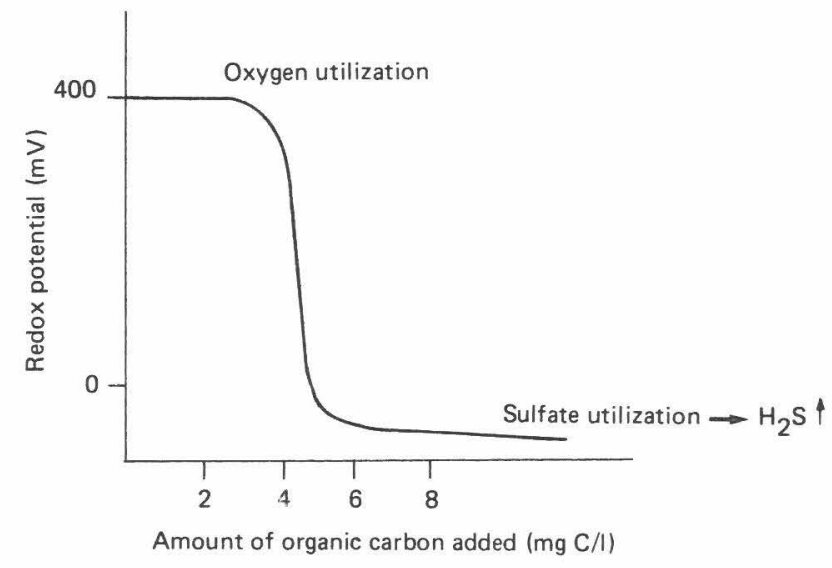

Figure 17 Mechanism for production of toxic $\mathrm{H}_{2} \mathrm{~S}$ in marine waters with an abundance of organic carbon, and restricted circulation of surface waters. Because of the relative abundance of sulfates in marine waters with respect to other oxygen-bearing molecules, reduction of sulfate is the dominant reaction under anaerobic conditions.

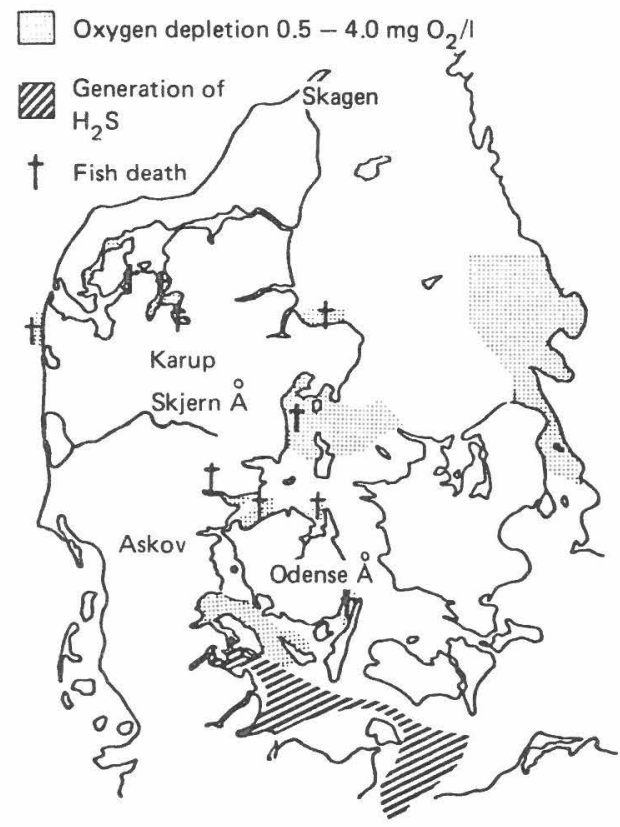

Figure 18 Coastal areas in which oxygen depletion, fish suffocation, and generation of $\mathrm{H}_{2} \mathrm{~S}$ were recorded in September 1981. Source: Miljostyrelsen, 1984. 
new environments, sudden changes in redox potential may occur, as for example, when sediments pulled from anoxic waters are exposed to the atmosphere. In industrialized countries, such sediments are usually highly contaminated with toxic heavy metals, pesticides, and other industrial pollutants. Whereas these chemicals may be relatively immobile under the redox conditions of the under water environment, a change in redox conditions may render them much more available for biological up-take with serious environmental consequences.

It should be noted that the great rivers flowing through industrialized countries of Europe, North America, eastern Asia, and elsewhere are the recipients of enormous quantities of toxic materials generated from industrial and agricultural activities conducted within their drainage basins. While great quantities of these materials are deposited in the rivers' sediments, huge amounts are also transported to the estuaries and the coastal zones at the rivers' mouths. Although spectacular industrial accidents causing a large pulse of polluting chemicals to enter the river (but with short-lived effects) often are the focus of attention in the media, the problem of toxic materials accumulating year by year in the water courses and coastal areas may be far more serious. For example, in a well-publicized industrial accident on the Rhine River at Basel in November, 1986, 33 tons of toxic chemicals were released to the river. In comparison, the annual discharge of the Rhine into the North Sea contains more than 10,000 tons of toxic chemicals, and the total quantity of chemicals released from the single accident was about equal to one day's normal discharge of chemicals at the river's mouth (Clark, 1986a). When viewed over many decades, the problem becomes more critical, for these great rivers have effectively transported hundreds of thousands of tons of toxic materials downstream and into the estuaries and coastal zones. As shown in Figure 19, evidence from sediment cores taken from coastal waters of the North and Baltic Seas indicates that toxic heavy metals have been accumulating for well over 100 years.

One of the most polluted of all regions is the Delta area in the Netherlands, where not only the Rhine, but also the Scheldt and the Meuse empty into the North Sea. To keep navigation lanes open in the Nieuwe Waterweg and adjacent ports of Rotterdam, about 50,000,000 tons (approx. 20,000,000 cu. meters) of spoil are dredged annually (V\&W, 1987). Table 3 shows the concentrations of eight heavy metals in the sediments of the Scheldt and Rhine estuaries in the 1970s. To place these values in perspective, the Dutch government in 1983 established some concentration standards for defining contaminated soils. For heavy metals these were soils with concentrations higher than the following: arsenic (20 ppm), cadmium (1 ppm), chromium (100 ppm), copper $(50 \mathrm{ppm})$, lead $(50 \mathrm{ppm})$, mercury $(0.5 \mathrm{ppm})$, nickel (50 ppm), and zinc (200 ppm) (VROM, 1980). Formerly, the dredge spoil was used to fill polder land in the Netherlands. However, as one may observe in Table 4, this practice polluted the land so badly that such deposits are now forbidden by law. Currently, dredge spoils of the 
Table 3. Metals in the Sediments of the Scheldt and Rhine Estuaries

\begin{tabular}{|c|c|c|c|c|c|c|c|c|}
\hline (mg per kg dry matter) & $\begin{array}{l}\text { Ars- } \\
\text { enic }\end{array}$ & $\begin{array}{l}\text { Cad- } \\
\text { mium }\end{array}$ & $\begin{array}{l}\text { Chro- } \\
\text { mium }\end{array}$ & $\begin{array}{l}\text { Cop- } \\
\text { per }\end{array}$ & $\begin{array}{l}\text { Merc- } \\
\text { ury }\end{array}$ & Lead & Nickel & Zinc \\
\hline \multicolumn{9}{|l|}{ Antwerp } \\
\hline 1974 & 84 & 37 & 510 & 200 & 3.8 & 260 & 71 & 1,500 \\
\hline 1979 & 94 & 35 & 290 & 180 & 3.0 & 260 & 60 & 990 \\
\hline \multicolumn{9}{|l|}{ Vissingen } \\
\hline 1974 & 18 & 1.2 & 100 & 29 & 0.7 & 65 & 24 & 180 \\
\hline 1979 & 21 & 2.0 & 100 & 28 & 0.5 & 46 & 26 & 170 \\
\hline \multicolumn{9}{|c|}{ Rijn-, Mass- and Waal ports } \\
\hline 1977 & - & 26 & 480 & 230 & 5.6 & 310 & 60 & 1,400 \\
\hline 1979 & 33 & 27 & 480 & 210 & 4.2 & 310 & 62 & 1,500 \\
\hline \multicolumn{9}{|l|}{ Europoort } \\
\hline 1977 & - & 3.2 & 130 & 42 & 1.0 & 81 & 25 & 290 \\
\hline 1979 & 18 & 3.7 & 150 & 38 & 0.9 & 80 & 27 & 310 \\
\hline
\end{tabular}

Sources: IB, 1987a, WL, 1987.

Table 4. Metals and Organochloro Compounds in the Soils of Polders Raised with Dredging Spoil from Rotterdam Ports, 1973-1978

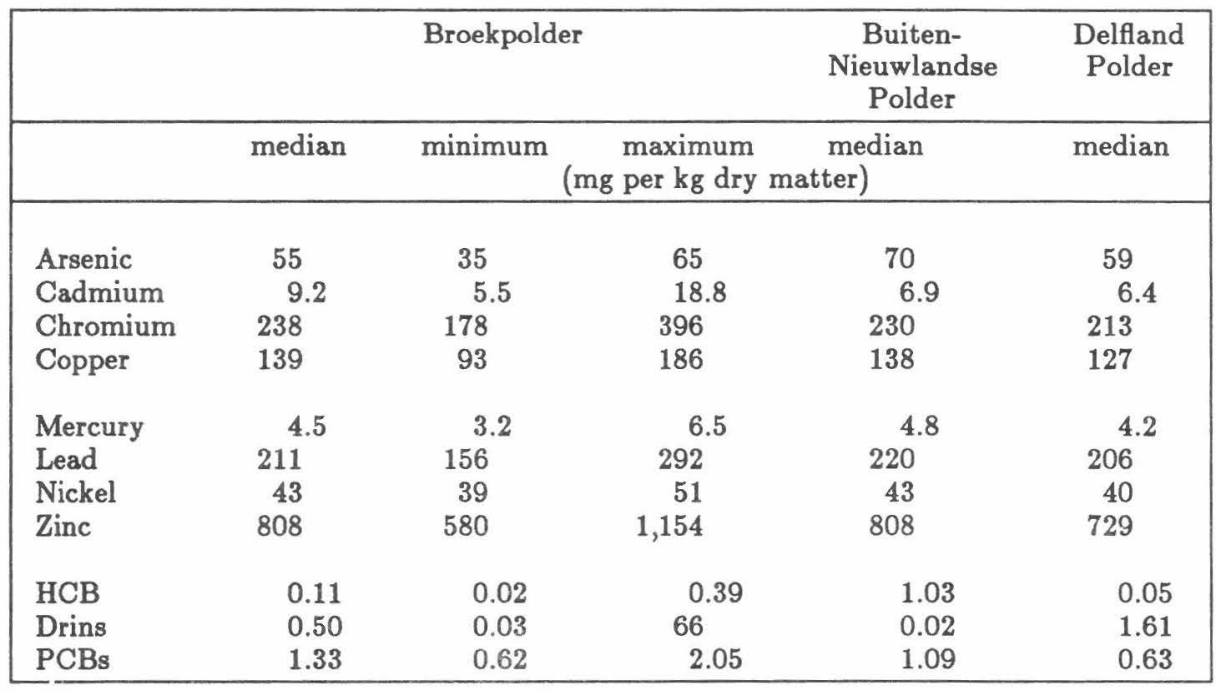

Source: IB, $1987 \mathrm{~b}$. 
GERMAN BIGHT (North Sea)

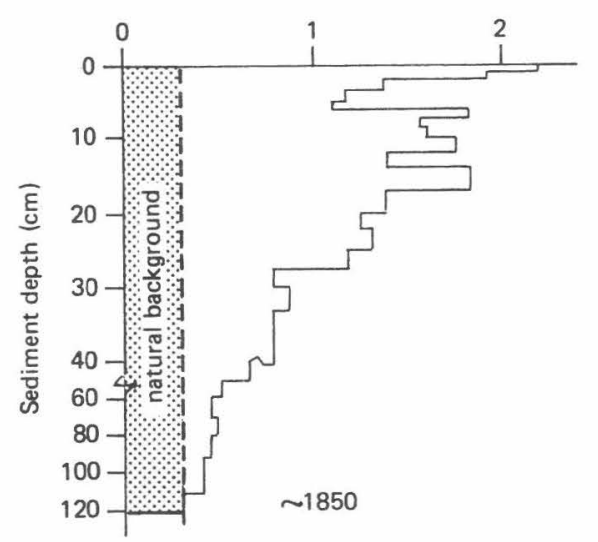

KIELER BUCHT (Baltic Sea)

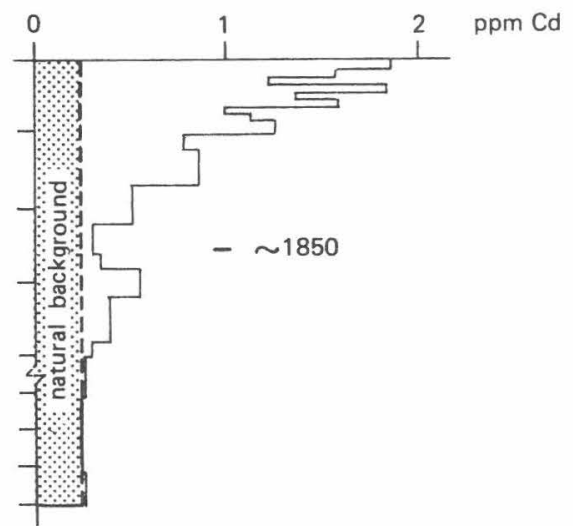

Figure 19 Chronological development of cadmium concentration in the North Sea and Baltic Sea as derived from analyses of sediment cores from the German Bight and Kieler Bucht. Source: Foerstner, 1980 and references cited therein.

Dutch coastal areas are a massive solid waste problem that remains unsolved.

\subsubsection{Changes in Redox Potential as a Major Source of Release of Toxic Materials from Dredge Spoils}

In sulfate-rich estuarine and marine ecosystems under anaerobic conditions, toxic heavy metals are often trapped in sediments as insoluble sulfides and organically bound species, forms that are relatively immobile and not readily available for bioaccumulation. The anaerobic condition may be maintained by the excessive quantities of organic carbon and nutrients often found in these waters, the result of upstream inputs from industrial and agricultural activities and domestic sewage. Thus, the sediments of highly polluted coastal areas fed by major water courses such as the Rhine serve as vast depositories for accumulated toxic wastes, often present in an environment that generally suppresses their toxicity. However, as shown in Figure 20, under certain changing physiochemical conditions accompanied by mechanical disturbance, the sediments can be a source of release of these chemicals, rather than a sink for their retention.

As noted by Foerstner (1986), the remobilization of heavy metals from sediments can be increased by four factors: (1) changing the redox conditions; (2) lowering the $\mathrm{pH}$; (3) increasing the salt concentration; and (4) increasing the occurrence of natural and synthetic complexing agents which can form soluble metal complexes. Furthermore, mechanical perturbation (erosion, dredging, bioturbation) can also affect remobilization of metals. In our discussion we will mainly focus on factors 1 and 2. It is important to mention however, that factor 3 may play an important determining role when, for example, harbor sludge from 


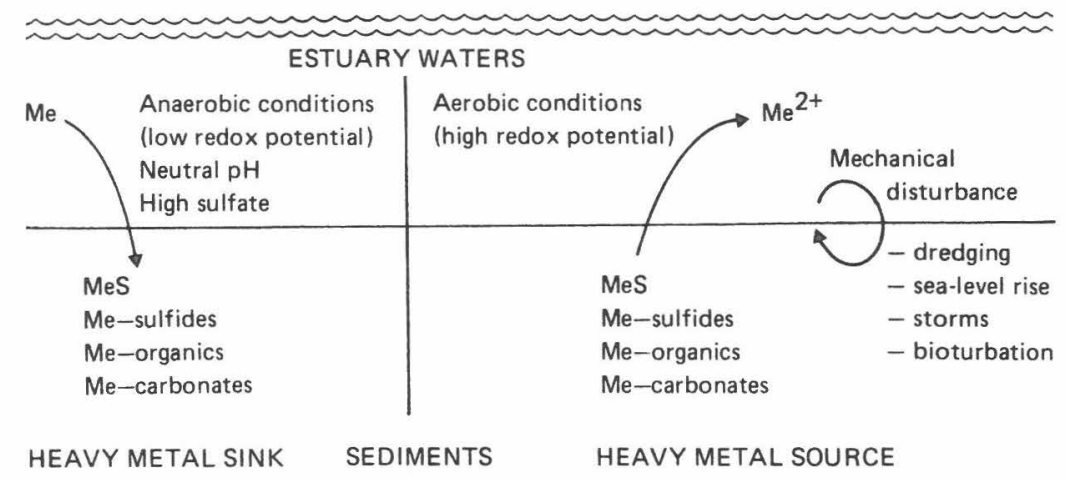

Figure 20 Estuarine sediments as a sink and a source of pollution by heavy metals, (Me).

inland areas is dumped into outer, more saline estuarine areas. This method of disposal may increase considerably in the future as national governments regulate more stringently, the option of deposition in land-fill areas (Prause et al., 1985). Figure 21 shows the remobilization of cadmium from contaminated sediments in the Weser River near Bremen upon exposure to estuarine conditions. It was suggested by Prause et al. that in the river sludge, cadmium was bound to the SH-group of organic material. Upon dumping in the outer estuary, this bonding position was broken as bacterial activity oxidized the SH-group to sulfate during the decomposition of the organic matter. So apparently, even the observed effect of increased remobilization with increasing salinity may be intricately linked to changes in redox potential. The remobilization mechanism appears to be metal-specific, however, since lead, which is characterized by its high affinity to particle surfaces, exhibits no tendency for remobilization. Also Compeau and Bartha (1984) postulate an inverse correlation of salinity with mercury methylation due to the reduction, in low-redox-potential marine environments, of sulfate to $\mathrm{H}_{2} \mathrm{~S}$, an inhibitor of methylation.

Mobilization via factor 4 will not be discussed further. There have been some studies suggesting that complexing agents have increased the mobility of heavy metals in some cases. The most well-known example is that of nitrilotriacetate (NTA), a substitute for polyphosphates in detergents. Several studies have demonstrated the effect of NTA on the remobilization of metals from sediments (Salomons and Van Pagee, 1981; Salomons, 1983).

The influence of $\mathrm{pH}$ and redox potential on the biological availability of heavy metals is exemplified for the case of cadmium in Figure 22. One may observe that under oxidized conditions at $\mathrm{pH}$ values less than 7 , the cadmium is mostly available in water-soluble form $\left(\mathrm{Cd}^{+2}\right)$. At pHs of about 8 and higher, cadmium concentration is governed by the solid phase $\left(\mathrm{CdCO}_{3}\right)$, which is biologically unavailable. At very high values of $\mathrm{pH}$ (10 or greater which is not very common in natural sys- 


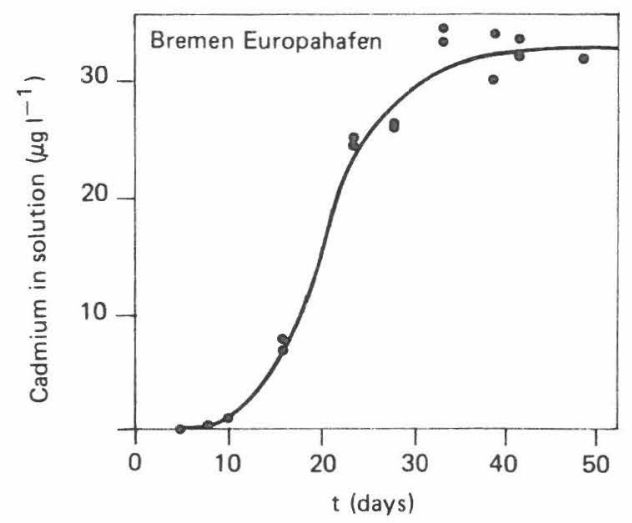

Figure 21 Remobilization of cadmium as a function of time upon exposing harbor sludge to saline conditions typical of outer-estuarine areas. The sludge is from the Europahafen Bremen, resuspended in seawater $32 / \mathrm{oo} ; \mathrm{pH}=7.9$; temp. $=7^{\circ} \mathrm{C} ; O_{2}=9 \mathrm{mg} / \mathrm{l} ; 10 \mathrm{~g}$ solids $/ 1$. Source: Prause et al., 1985.

tems) soluble forms of cadmium again predominate. On the other hand, under reducing conditions $(\mathrm{Eh}<0)$ cadmium is present predominantly as the insoluble sulfide. As described previously, such would be the typical case in anoxic marine sediments. In natural environments the chemistry of cadmium is more complex than depicted in Figure 22. The metal may exist not only as precipitated sulfide, but also in other solid phases as well; e.g., as precipitated organically-bound species. Nevertheless, the overall effect of exposing these sediments to oxygen is a large increase in the potential mobility of these metals;

$$
\mathrm{MeS}(\text { solid })+\mathrm{O}_{2}+\mathrm{H}_{2} \mathrm{O} \rightarrow \mathrm{Me}^{+n}(\text { mobile })+\mathrm{SO}_{4}^{-2}+2 \mathrm{H}^{+}
$$

(See also Table 2 , reaction $4 \mathrm{~b}$ )

As shown in the above reaction, the oxidation may also be accompanied by an increase in acidity $\left(\mathrm{H}^{+}\right)$. Referring again to Figure 22, one may observe that an increase in both acidity and in redox potential greatly favors the soluble form of cadmium.

Indeed, greatly increased mobility of cadmium and increased acidity have been observed in field studies when near-neutral $\mathrm{pH}$, noncalcareous, dredged sediments high in sulfide and organic matter were exposed to oxidized conditions at upland disposal cites (Gambrell et al., 1977; Khalid, 1980). De Groot (1977) studied the uptake of cadmium by several agricultural crops from highly polluted Rotterdam Harbor sediments dumped at upland sites. The crops grown on dredged sediments showed a significantly higher content of cadmium than the crops grown on natural river clays. An exponential increase in cadmium uptake was observed with increasing concentrations of the element, especially in leafy vegetable and rootlike crops including lettuce, radishes, potatoes, and carrots. More recently, Kersten and Foerstner (1987) have obtained similar results. 


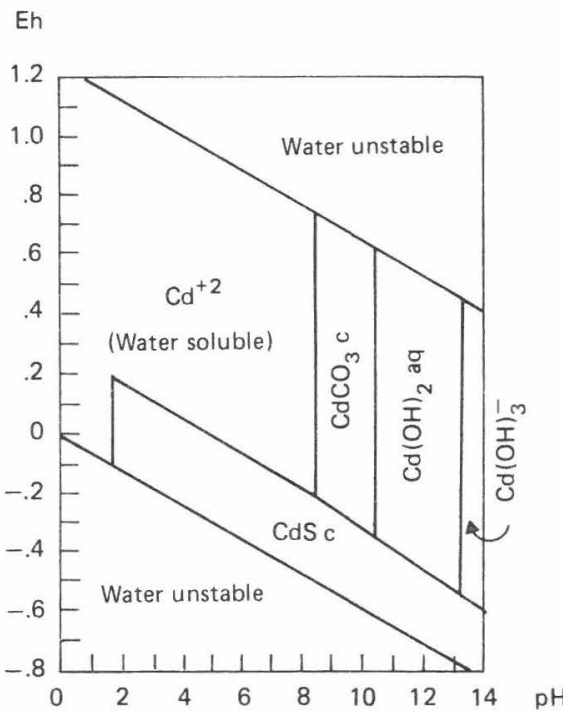

Figure 22 Fields of stability of solids (signified by c) and predominant dissolved cadmium species in system $\mathrm{Cd}+\mathrm{CO}_{2}+\mathrm{S}+\mathrm{H}_{2} \mathrm{O}$ at $25^{\circ} \mathrm{C}$ and $1 \mathrm{~atm}$ in relation to redox potential $(\mathrm{Eh})$ and $\mathrm{pH}$. Dissolved cadmium activity, $10^{-7.05}$ $\mathrm{mol} / \mathrm{l}$; dissolved $\mathrm{CO}_{2}$ and $\mathrm{S}$ species, $10^{-3} \mathrm{~mol} / \mathrm{l}$. Source: Hem, 1972.

Gambrell et al. (1980) studied the chemical availability of mercury, lead, and zinc in Mobile Bay (USA) sediment under varying $\mathrm{pH}$ and redox conditions. They established that the biological availability of these metals was dependent on $\mathrm{pH}$ and redox conditions. They further noted, however, that when the transit time between dredging and disposal is short, there is little opportunity for the reduced, bulk solid material to oxidize before settling to the bottom of a disposal site. So over the short term there might be little observable effect. The real concern, however, is the possible releases of toxic metals caused by longterm alterations in the physiochemical environment of the designated disposal site. They recommended, therefore, that in selecting a disposal alternative, information on the potential for such long-term physiochemical changes should be factored into the management strategy.

A similar concern was raised by Berman and Bartha (1986), in a study of mercury polluted sediments in an estuarine creek in New Jersey, USA. They noted that the mercury under the prevailing conditions $(\mathrm{pH}=6.8, \mathrm{Eh}=-230 \mathrm{mV})$ and high sulfide environment would remain relatively immobile and harmless to biota. However, they cautioned that if ever there is a "cleanup of the contaminated sediments by dredging, it will be critical to minimize any air exposure and weathering of the dredge spoils. A speedy entombment of the $\mathrm{Hg}$-contaminated dredge spoils in an anoxic sulfide-rich state, with provisions for permanent exclusion of oxygen and oxygenated ground water appears to be a long-range disposal option". 
Interestingly, in the same paper, Berman and Bartha reflect briefly upon two plausible events by which the immobile, sulfur-bound mercury could be transformed into the highly toxic and bioavailable methlylated species. One is the possibility of a storm flood that might transport some of the contaminated sediment to other areas of the estuary more conducive to the production of methyl mercury; i.e., conditions of lower $\mathrm{pH}$ and/or higher redox potential. ${ }^{6}$ The other possibility is, paradoxically, an improvement in the water quality due to sewage diversion that might lead to lower sulfide concentrations (and higher redox potentials), and hence a subsequent increase in $\mathrm{Hg}$ methylation activity.

\subsection{Potential Vulnerabilities in the Future}

\subsubsection{Estuaries and Coastal Marine Areas}

Thus far in this section, we have established that the mobilities of toxic metals are highly dependent on changes in redox potential, $\mathrm{pH}$, and to some degree salinity. The physiochemical conditions in which marine and estuarine sediments tend to serve as sinks for toxic heavy metals are low redox potential (anoxic conditions) and near-neutral $\mathrm{pH}$. The sediments can suddenly become a source of toxic metals when the opposite conditions prevail; i.e., increases in redox potential and decreases in $\mathrm{pH}$.

Using again the "bottom-up approach" described earlier, it may be useful to imagine how some of the determining factors described here could be influenced by future activities. Since the question of future possibilities for increased acidity was treated in previous sections, we will not dwell on it here. Moreover, acidification of estuarine and marine areas is not likely to occur. However, acidification may be an important factor in upland disposal sites; i.e., if such sites continue to acidify in the future, increased leaching of toxic materials may occur.

With regard to broad scale changes in redox potential, we may again recall Berman and Bartha's rather paradoxical idea about an increased risk of mercury mobilization in the event of a clean-up of sewage emptying into the estuary. On the other hand, this is not so paradoxical if we recall that the effect of sewage wastes in water bodies is to reduce the redox potential and to foster anoxic conditions, which are precisely the conditions that suppress the mobilization of heavy metals.

\footnotetext{
${ }^{6}$ Berman and Bartha concluded that the high levels of sulfide $\left(S^{-}\right)$inhibited methylmercury formation. This is so because the equilibrium constant $\left(K_{s}\right)$ for the reaction, $\mathrm{Hg}^{+2}+\mathrm{S}^{-2} \rightarrow \mathrm{HgS}(\mathrm{s})$ is $10^{-52}$. This very low value means that in the presence of sulfide, essentially all of the $\mathrm{Hg}$ will appear as $\mathrm{HgS}(\mathrm{s})$. However, the activity of $\mathrm{S}$ can be decreased, and that of $\mathrm{Hg}$ increased, by lowering the $\mathrm{pH}$ and/or increasing the redox potential. For details, see Wood (1980), and Bjornberg et al. (1988).
} 
We have seen that the great rivers, estuaries, and coastal areas of Europe are now unwittingly huge toxic waste dumps. What will be the effect on these contaminated sediments, if there is an improvement in water quality, through stricter regulations for the discharge of sewage wastes, and reductions in runoff of nitrogen fertilizers to these water bodies? Many nations in Western Europe are already moving in those directions. If, as mentioned previously, agricultural activity is reduced by at least $20 \%$, there could be even larger decreases in discharge of nitrate.

A few laboratory studies have been conducted in order to ascertain the effects of the relaxation of pollution pressure on heavily contaminated sediments. As shown in Figure 23, Chen et al. (1976) and Lu and Chen (1977) demonstrated that such sediments release metals when maintained under oxidizing conditions. Hunt and Smith (1983) studied the fluxes of remobilization of copper, lead, iron, manganese, and cadmium from sediments in highly polluted Narragansett Bay (Rhode Island, USA). They isolated representative samples of these sediments from heavy metal inputs, and examined them under organic loading factors reduced by $60 \%$ relative to current loading. They concluded

that there was a tendency for the polluted sediments to purge themselves. They also demonstrated that the so-called "bleeding" of toxic metals from the sediments under the conditions of improved water quality generally occurred at rates considerably lower than were the current inputs to the sediments. The results are shown in Table 5. Nevertheless, one may observe that the rate of cadmium remobilization was calculated to be a not-insignificant $15 \%$ of the current cadmium

Effect of Physicochemical Parameters on Cadmium Mobility

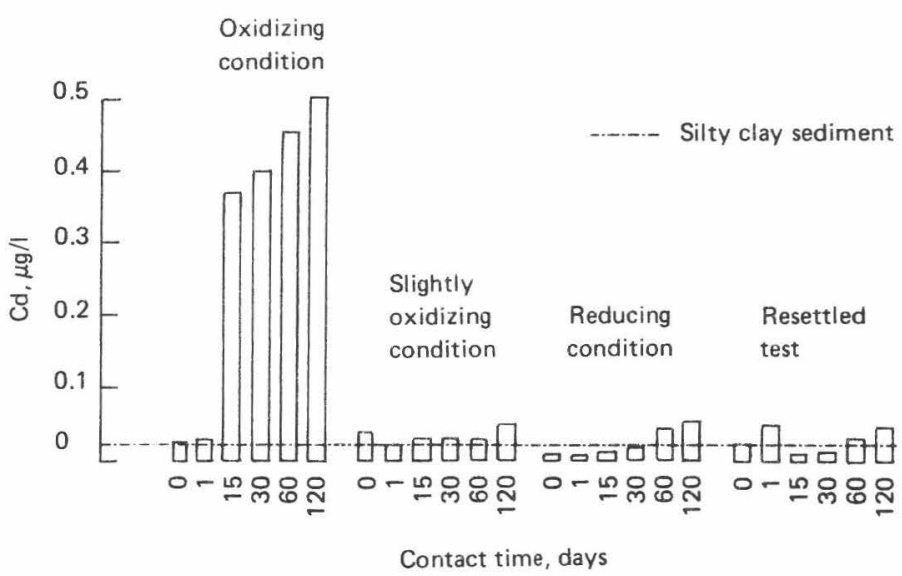

Figure 29 The effect of various oxidation-reduction conditions on the mobility of cadmium in sediment-seawater interfaces in a silty clay sediment. Source: Chen et al., 1976. 
inputs. One should also consider that under the physiochemical conditions of the highly polluted Bay, the sediments are a sink for these metal inputs, and under these conditions their potential toxicity is highly suppressed. The remobilized cadmium, however, under conditions of improved water quality would be much more readily available for biological uptake. Another conclusion drawn from this study was that, at least for some of the metals, the purging time (for the top 15 $\mathrm{cm}$ of sediment) was on the order of centuries. (For example, about 400 years for copper.)

Table 5. Comparison of the Daily Input of $\mathrm{Cu}, \mathrm{Pb}$, and $\mathrm{Cd}$ to Naragansett Bay with the Calculated Output from Remobilization Under Conditions of Improved Water Quality

\begin{tabular}{|c|c|c|c|}
\hline \multirow[b]{2}{*}{ Metal } & \multirow[b]{2}{*}{$\begin{array}{c}\text { Current } \\
\text { Inputs to Bay } \\
\left(\mathrm{mol} \times d^{-1}\right)^{b}\end{array}$} & \multicolumn{2}{|c|}{ Remobilized from Sediment ${ }^{a}$} \\
\hline & & $\begin{array}{l}\text { Providence River } \\
\quad\left(\mathrm{mol} \mathrm{x} d^{-1}\right)^{b}\end{array}$ & $\begin{array}{l}\text { Upper Bay } \\
\left(\mathrm{mol} \times d^{-1}\right)^{b}\end{array}$ \\
\hline $\mathrm{Cd}$ & 48 & 2 & 5 \\
\hline $\mathrm{Cu}$ & 3000 & 46 & 100 \\
\hline $\mathrm{Pb}$ & 780 & 1 & 2.5 \\
\hline
\end{tabular}

a) Under conditions of improved water quality.

b) The term in parentheses signifies "moles per day". A "mole" is an "atomic-weight" number of grams. Thus 1 mole of cadmium weighs 112 grams, since 112 is the atomic weight of cadmium.

Source: Hunt and Smith, 1983.

Another important consideration about potential problems in the future regards the impact of climatic change (from increasing levels of $\mathrm{CO}_{2}$ and other greenhouse gases) on the contaminated sediments, particularly the possibility of increased coastal storm events, and the potential effects of sea level rise. Climatologists generally agree that there will be an increase in the frequency of extreme events, and presumably this means storm events as well. Will more frequent sea storm surges increase the stirring up of the sediments; perhaps moving them to new environments more conducive to remobilization, or mixing them with more oxygenated surface waters? And what would be the effect, say, of an $80 \mathrm{~cm}$ sea level rise on the coastal and estuarine sediments? Will the encroaching seas further stir up and transport the sediments so as to render them more mobilizable? Will there be increased salinity in the inland reaches of the estuary systems, and will this increase lead to increased mobilization? These are important questions that deserve answers well before such events are upon us.

\subsubsection{Inland Freshwater Systems}

Under conditions of high redox potential, sediments of freshwater 
systems may contain high concentrations of iron and manganese oxides. As discussed in Table 2, these oxides, which are insoluble, effectively adsorb heavy metals and other toxic materials. Notably, in contrast to the case for oxidation and reduction of metal sulfides, iron and manganese oxides tend to release adsorbed toxic materials under reducing conditions. (See Figure 16 which depicts the release of toxic materials, designated by $\mathrm{X}$, upon reduction of $\mathrm{MnO}_{2}$ and $\mathrm{Fe}(\mathrm{OH})_{3}$; see also reactions $3 \mathrm{a}$ and $3 \mathrm{~b}$ in Table 2, and compare with reaction $4 \mathrm{~b}$, showing the release of toxic heavy metals (Me) upon oxidation of sulfide.)

Hence, whereas anoxic estuarine and marine sediments may release toxic materials under conditions of improved water quality (i.e., increased redox potential), the opposite condition may prevail in the above-cited frcshwater system. Thus, in well-oxygenated lakes, sediments containing toxic materials scavenged and deposited by iron and manganese oxides may release the materials under conditions of decreasing redox potential (R. Wollast, Free Univeristy of Brussels, personal communication, 1988). Such conditions may be triggered, for example, by eutrophication, which, in the absence of nitrate, will cause the redox potential of the lake water to decrease to the levels required for the reduction of $\mathrm{MnO}_{2}$ and $\mathrm{Fe}(\mathrm{OH})_{3}$. In terms of the potential for such occurrences in the future, it was noted in section 3.1 that phosphate saturation of agricultural soils and subsequent leaching of phosphorus to water bodies could cause a new wave of eutrophication in the coming decades. Moreover, a significant increase in the rate of eutrophication may occur owing to rising average annual temeperatures caused by climatic change. An increase of only a few degrees Centigrade may substantially accelerate the microbiological reactions governing eutrophication (R. Wollast, Free University of Brussels, personal communication, 1986).

\subsection{Wetlands as Sinks for Sulfates, Nitrates, and Toxic Metals}

\subsubsection{Sulfates}

As described by Bayley et al. (1986), freshwater wetlands may serve as a sink for sulfate. The mechanism of sulfate storage is illustrated in Figure 24. The sources of sulfur may be from acid deposition, or sulfur-containing minerals such as gypsum and pyrite. Because of the anaerobic conditions existing in the wetlands, sulfate is reduced to immobile sulfide compounds. (See Table 2, reaction 4a.) The degree of sulfur storage depends on the hydrological conditions and the residence time of the sulfate in the wetland, but it can be substantial. Braekke (1981) observed as much as $35 \%$ retention of sulfate in a peatlanddominated watershed in southern Norway. Calles (1983) observed a $25 \%$ to $64 \%$ retention of sulfate in two Swedish watersheds containing $8 \%$ and $33 \%$ bog areas, respectively. By this mechanism, wetlands may contribute substantially to decreasing sulfate concentrations of water passing through them (Vitt and Bayley, 1984; Wieder and Land, 1984). 
Alternatively, during hot dry summers, wetlands may become a source of sulfate. Under these conditions the level of water drops, and the reduced sulfur compounds above the water level become exposed to oxygen. The compounds are oxidized to sulfate, and may subsequently be flushed during heavy rain storms to downstream waters. This phenomenon has been observed for example in Norway (Braekke, 1981), and England (Rippon et al., 1980; Brown, 1980). The hydrological factors that appear to be the most important in determining annual sulfur retention are depth and frequency of flooding, and the total amount of precipitation.

\subsubsection{Nitrates}

As shown in Figure 24, an analogous situation occurs for nitrates. Under anaerobic conditions in the presence of abundant nitrates and organic carbon, bacterial decomposition of carbon will occur via the reduction of nitrate to $\mathrm{N}_{2}$ or $\mathrm{N}_{2} \mathrm{O}$. (See Table 2, reaction 2.) One may view this system as a nitrate trap, since the reduced nitrogen products are vented to the atmosphere. This effect occurs, for example, when nitrate-rich waters pass through water-logged soils rich in organic carbon. In certain situations where high concentrations of nitrate are a potential pollution problem, the system may have a beneficial function, serving to deplete nitrate before it can enter downstream waters. This function has been observed, for example, in the Garrone Valley in southern France (Pinay and De Camps, 1988), and in southern Sweden (Fleischer and Hamrin, 1987; Jannsson et al., 1986).

On the contrary, when the wetlands dry out, nitrate may enter the downstream waters without losses. This situation can affect water quality owing to increased loadings of nitrate.

\subsubsection{Toxic Metals}

Wetlands provide anaerobic environments where certain toxic metals may accumulate as precipitated sulfides and other insoluble salts. A problem may arise in wetland areas heavily impacted by inputs of these toxic metals in previous decades. Drying of these lands will lead to an increase in the redox potential, and the metals may oxidize, forming more soluble products that may leach to the wider environment.

Obviously, there is a strong linkage between wetland function and climate. This issue is discussed in the following section. 


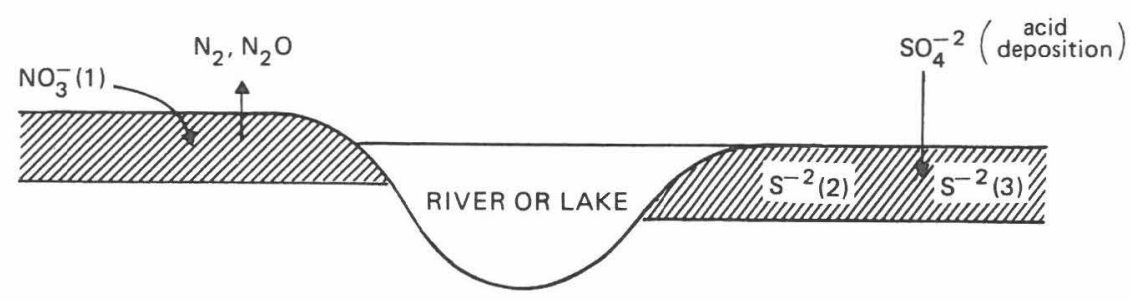

Wetlands as a Sink for Nitrate and Sulfate

(a)

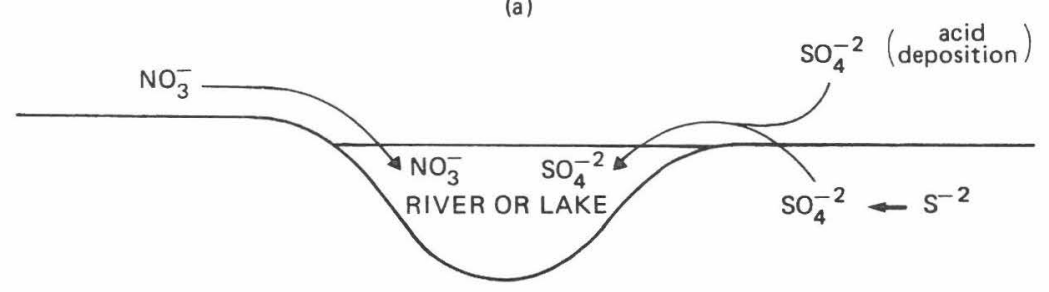

Dry Land as a Transporter of Nitrate and Sulfate

(b)

\footnotetext{
${ }^{1}$ Nitrate from runoff of nitrogenous fertilizer

${ }^{2}$ Sulfide minerals from former marine sediments

${ }^{3}$ Sulfide reduced from sulfate inputs of acid deposition
}

Figure $2 \&$ (a) Ability of wetlands to buffer against nitrate and sulfate inputs to water bodies. Nitrate is reduced to molecular nitrogen $\left(N_{2}\right)$ or nitrous oxide $\left(\mathrm{N}_{2} \mathrm{O}\right)$, both of which are vented to the atmosphere. Sulfate $\left(\mathrm{SO}_{4}^{-2}\right)$ is reduced to sulfide $\left(S^{-2}\right)$, which forms an insoluble precipitate in wetland soils. (b) Under conditions where wetlands become dry, none of the protective reducing reactions occur. In addition, sulfides that were stored in wetland soils may become oxidized and leach into water bodies. Shaded area indicates region of wetlands.

\section{OVERVIEW: DEVELOPMENT/ENIVRONMENT INTERACTIONS AND THE POTENTIAL FOR SURPRISES}

\subsection{Introduction}

In order to plan an effective strategy for managing long-term environmental changes, including a means for anticipating surprises ${ }^{7}$ it is necessary to understand the interactions that define the relationships between development activities and the environment. As discussed by Clark (1986b), it is rare that one human activity affects just one aspect

${ }^{7}$ We define surprise here as an ecological change that may occur over a period of time
that is short relative to the response time required for implementing mitigation strategies. 
of the environment. Also, conversely, it is rare that one environmental problem is caused solely by just one kind of human activity. Instead, in most cases the development activities are linked to environmental transformations in rather complicated ways. Understanding the intricacies of these linkages is what Clark has defined as a "synoptic" vision. One of the great problems in environmental management is the question of how to synthesize the substantial, yet imperfect, knowledge already gleaned from ongoing research on the biosphere, in a way that will be usable for the long-term, strategic management of the environment. One method, described by Clark (1986b) and Crutzen and Graedel (1986), employs a two dimensional matrix that identifies the sources (causes) of environmental change on one axis (including natural sources), and a small set of "critical environmental indicators"8 (CEIs) on the other axis. Such indicators may be viewed simply as attributes of the environment that some party to the assessment believes to be important. This approach is attractive for two reasons: 1) it incorporates the synoptic approach to complex inter-relationships between economic development and environmental change; and 2) by condensing down the number of indicators to a definite, and preferably small set, it makes such an analysis "do-able."

The success of this approach of course depends on choosing a set of CEIs that will serve the goals of the assessment well. In addition, it is also necessary, to the extent possible, to identify not only the primary linkages between development activities and environmental transformations (represented as changes in the CEIs), but also to identify secondary linkages. That is to say, a specific development activity A may affect a given critical environmental indicator through an intermediate influence on indicator $B$. In my view one of the major clues to anticipating "surprise" environmental changes is a deeper understanding of second order interactions. For it is often these interactions that camouflage the linkages between primary causes and environmental effects.

In this section we will adopt the suggested matrix approach described above. Human activities are defined in four general areas: energy use, agricultural activities, industrial activities, and commercial and domestic activities. Our CEIs will be the three "capacities" presented in the previous sections, plus "toxic chemicals accumulation", which is of course related to the other three CEIs, but is of such interest that it is highlighted here as an additional indicator. We first describe the primary interactions, as presented in Table 6, then the secondary interactions shown in Table 7 , and finally a combined table (Table 8) which describes both primary and secondary interactions.

\footnotetext{
${ }^{8}$ Clark (1986b) actually described what I call critical environmental indicators as "valued environmental components", the concept of which was developed in Beanlands and Duinker (1983). I prefer my definition in the context of this paper for simple semantic reasons. One of my CEIs, "Toxic materials accumulation", is hardly a "valued" component.
} 
Since many of the topics have been discussed at length in earlier sections of this paper, their descriptions here will be brief, and the reader may refer back to the relevant sections for more details.

\subsection{Primary Interactions: Table 6}

\section{Interactions from Energy Use (Boxes 1 and 4)}

Moving horizontally across Table 6, one may observe that energy production (in this case the burning of fossil fuels) causes a depletion of buffering capacities in soils through acid deposition. Also, fossil fuels contain trace quantities of heavy metals which are volatilized during combustion, transported through the atmosphere, and deposited in the environment. Another toxic by-product of combustion is the formation of a class of organic chemicals named polynuclear aromatic hydrocarbons (PAHs). These are distributed in the environment by a mechanism similar to that of toxic heavy metals.

\section{Interactions from Agricultural Activities (Boxes 5-8)}

Buffering capacities of agricultural soils are maintained by the application of lime, $\mathrm{Ca}(\mathrm{OH})_{2}$. Approximately $50 \%$ of European land is used for agriculture, and a large fraction of this land is regularly limed. In contrast to acid deposition, liming replenishes, rather than depletes agricultural soils. The effects of acid deposition have already affected the amounts of lime applied in the most acid-sensitive soils. For example, Swedish farmers, at a significant cost, have increased application rates in recent years to offset the effects of acid deposition ( $R$. Wright, Norwegian Institute for Water Research, Oslo, personal communication, 1988).

Application of phosphate fertilizer has led to the accumulation of phosphorus in soils, resulting in depletion of the phosphorus sorption capacity. Also, some heavy metals and certain pesticides have accumulated in agricultural soils. Cadmium, present as an impurity of phosphate fertilizers, is applied inadvertently during fertilizer application. The same is true of other toxic metals from contaminated manure and sewage sludges used as fertilizers.

Agricultural activities also greatly affect the redox potential of water bodies, mainly through runoff and leaching of nitrate fertilizer. Currently, levels of nitrates in river waters emptying into the North Sea are as m.ich as 30 to 40 times higher than background levels (Wollast, 1983). The nutrient-rich waters support a high degree of biological productivity. As described earlier, such conditions rapidly lead to anoxia and lowered redox potential.

Agriculture also directly contributes to the accumulatic a of toxic materials in the environment. In addition to accumulation in agricultural soils (described in box 6), runoff of pesticides into water courses, or their seepage into groundwaters has occurred. 
Table 6. Development/Environment Interactions Primary Interactions

\begin{tabular}{|c|c|c|c|c|}
\hline Sources & Buffering Capacity & $\begin{array}{l}\text { Sorption Capacity } \\
\text { (Agricultural Soils) }\end{array}$ & Redox Potential & $\begin{array}{l}\text { Toxic Materials } \\
\text { Accumulation }\end{array}$ \\
\hline Energy Use & 1 & 2 & 3 & $\begin{array}{l}4 \\
\text { Heavy metals } \\
\text { PAHs }\end{array}$ \\
\hline $\begin{array}{l}\text { Agricultural } \\
\text { Activities }\end{array}$ & $\begin{array}{l}5 \\
\text { Liming }\end{array}$ & $\begin{array}{l}6 \\
\text { Phosphate application; } \\
\text { cadmium, other } \\
\text { heavy metals, } \\
\text { pesticides }\end{array}$ & $\begin{array}{l}7 \\
\text { Over-Fertilization } \\
\text { by nitrate, } \\
\text { subsequent discharge } \\
\text { to water }\end{array}$ & $\begin{array}{l}8 \\
\text { Pesticide runoff }\end{array}$ \\
\hline $\begin{array}{l}\text { Industrial } \\
\text { Activities }\end{array}$ & 9 & 10 & $\begin{array}{l}11 \\
\text { Discharge to water } \\
\text { of organic carbon } \\
\text { chemicals with } \\
\text { high COD }\end{array}$ & $\begin{array}{l}12 \\
\text { Heavy metals; } \\
\text { toxic organic } \\
\text { chemicals }\end{array}$ \\
\hline $\begin{array}{l}\text { Commercial and } \\
\text { Domestic Activities }\end{array}$ & 13 & 14 & $\begin{array}{l}15 \\
\text { Discharge to water of } \\
\text { organic carbon chemicals } \\
\text { with high COD }\end{array}$ & $\begin{array}{l}16 \\
\text { Heavy metals; } \\
\text { toxic organic } \\
\text { chemicals }\end{array}$ \\
\hline
\end{tabular}


Interactions from Industrial Activities (Boxes 11 and 12)

Industry and manufacturing produce high volumes of carboncontaining wastes that place a high oxygen demand on receiving waters, thus affecting the redox potential of these waters. (An index of this demand is COD = carbon oxygen demand.) Major sources of pollution are manufacturers of food (animal products) and beverages, tobacco products, the chemical industry, and paper and board mills. Industrial and manufacturing wastes are responsible for about half of the total COD in European water systems; domestic sewage provides the other half. In heavily polluted rivers like the Scheldt, long stretches (tens of $\mathrm{km}$ ) have been known to become completely anoxic. Under these conditions, organic carbon accumulates and is transported in dissolved or particulate form to the estuaries and coastal regions. The increased flow of carbon with high COD rapidly leads to anoxic conditions in these regions as well.

Industrial activities also generate large quantities of toxic wastes. These may be stored in land fills, or directly discharged to the air or water. Heavy metals are generated in the electroplating and metalfinishing industries, scrap metal recycling, the smelting of metal ores, and fossil fuel refining. Main sources of toxic organic wastes are the chemical and petrochemical industries.

\section{Interactions from Commercial and Domestic Activities (Boxes 15 and 16)}

A major source of environmental pollution also results from the day-to-day activities of human settlement, including work activities in the non-industrial sectors. The worse pollution is generated in large urban areas. One age-old problem has been the disposal of domestic and commercial sewage to water bodies. Untreated or partially treated sewage has high values of COD, and is a major cause of anoxia and low redox conditions in water courses.

Also there are many sources of toxic materials associated with domestic/commercial activities. A recent study in the U.S. of the toxic content of domestic garbage, estimated that the average household discarded approximately 55 to $60 \mathrm{~g}$ of hazardous waste per week. That amounts to about 642 metric tons of hazardous waste discarded per year for a city the size of New Orleans (population, about 600,000, Chemical and Engineering News, 1987). Burning of refuse may release some of these materials to the atmosphere, and may even create new toxic chemicals, as for example during the burning of plastics. Some of the refuse is buried in land fills, which may lead to eventual release through leaching.

Other sources of toxic materials may be released during the dissipative end uses of some consumer products. For example, asbestoscontaining brakes emit asbestos in the process of braking, lead is released to the atmosphere during the combustion of leaded gasoline, and organic solvents are released to the atmosphere in the processes of painting and dry-cleaning. The day-to-day corrosion of urban struc- 
tures may also be important, causing the release of heavy metals such as $\mathrm{Zn}, \mathrm{Fe}, \mathrm{Cu}$, and $\mathrm{Pb}$.

\subsection{Secondary Interactions: Table 7}

\section{Buffering Capacity/Sorption Capacity (Box 3)}

In the previous discussion, we explored the linkage between buffering capacity and sorption capacity in agricultural soils. We described how the buffering capacity, maintained by continual liming, generally serves to extend the soil's ability to adsorb toxic materials, and how conversely, the cessation of liming might result in the release of toxic materials, through a diminished sorption capacity.

\section{Buffering Capacity/Toxic Materials Accumulation (Box 4)}

Many examples from the literature on acid deposition demonstrate the effect of greatly increased leaching of toxic heavy metals from terrestrial ecosystems as soils acidify. Metals with the highest potential mobility in acidified soils are aluminum, cadmium, manganese, and zinc. Copper and nickel are also mobilized but not as readily as the first set (NRC, 1985).

\section{Redox Potential (Soils)/Buffering Capacity (Box 5)}

Earlier we described how wetlands may serve as a sink or a source for sulfate. (See Figure 24.) When wetlands containing sulfur are drained or dry out naturally, the redox potential increases and sulfide is oxidized to sulfate. In certain cases, as in areas heavily affected by acid deposition or in areas containing pyrite minerals, the sulfate may be flushed out as sulfuric acid, causing rapid acidification of soils and subsequent acidification of receiving waters.

A good example of this occurrence is the acidification of Lake Blamissusjon in northern Sweden (Renberg, 1986). Currently, the pH of this lake is about 3 , and it has been called "the most acidic lake in Sweden", even though its acidification was certainly not caused by acid deposition. The lake is situated in a coastal area near the Bothinian Bay. The water surface lies only 1 to $2 \mathrm{~m}$ above the current sea level, which, with an isostatic land rise in the area of about $0.9 \mathrm{~cm}$ per year, means that the lake probably was isolated from the sea just two to three hundred years ago. Because the present-day watershed was previously under the sea, the soils were rich in reduced sulfide minerals. Until the beginning of this century the $\mathrm{pH}$ of the lake was probably 5.5 or higher. This condition prevailed as long as the watershed soils remained water-logged. But in this century, first around 1900, and then more extensively in the 1940s, the land was drained for agricultural purposes. These actions lowered the water-table of the watershed soils, thus exposing the sulfide minerals to oxidation. (See Table 2, reaction $4 \mathrm{~b}$ for more details.) Sulfide was oxidized to sulfuric acid, causing an extreme acidification of the soils, and subsequently of the lake. There has been no recovery of the $\mathrm{pH}$ levels in the lake, even though agricultural activities ceased by the end of the 1960s. 
Table 7. Development/Environment Interactions Secondary Interactions

\begin{tabular}{|c|c|c|c|c|}
\hline Sources & Buffering Capacity & Redox Potential & $\begin{array}{l}\text { Sorption Capacity } \\
\text { (Agricultural Soils) }\end{array}$ & $\begin{array}{l}\text { Toxic Materials } \\
\text { Accumulation }\end{array}$ \\
\hline Buffering Capacity & 1 & 2 & $\begin{array}{l}3 \\
\text { Liming resulting in } \\
\text { augmented sorption } \\
\text { capacities for heavy } \\
\text { metals, pesticides; } \\
\text { cessation of liming } \\
\text { resulting in diminished } \\
\text { sorption capacities }\end{array}$ & $\begin{array}{l}4 \\
\text { Diminished buffering } \\
\text { capacity from acid } \\
\text { deposition resulting in } \\
\text { increased leaching of } \\
\text { heavy metals from } \\
\text { terrestrial ecosystems }\end{array}$ \\
\hline Redox Potential & $\begin{array}{l}5 \\
\text { Drainage of wetlands } \\
\text { with high contents } \\
\text { of sulfide minerals, } \\
\text { causing acidification } \\
\text { through generation } \\
\text { of } \mathrm{H}_{2} \mathrm{SO}_{4}\end{array}$ & $\begin{array}{l}6 \\
\text { Submerged riparian } \\
\text { woods as sink for excess } \\
\text { nitrate before river } \\
\text { discharge; man-made } \\
\text { disturbance of woods } \\
\text { causing increased } \\
\text { discharge of nitrate } \\
\text { to rivers }\end{array}$ & 7 & $\begin{array}{l}8 \\
\text { Redox conditions in } \\
\text { water regulating whether } \\
\text { sediments are a sink or } \\
\text { a source of heavy metals }\end{array}$ \\
\hline
\end{tabular}


Redox Potential (Soils)/Redox Potential (Waters) (Box 6)

In a rich agricultural region in the Garonne Valley in southern France, Pinay and DeCamps (1988) have investigated the role of a partially submerged riparian woods as a buffer zone for the lateral transfer of nitrates from polluted groundwaters to the River Louge. They demonstrated that a flow of groundwater through about 30 meters of the submerged soil of the woods was sufficient to remove all the nitrate. They thus demonstrated in a larger sense the effectiveness of riparian wetland zones in protecting rivers from large inputs of nitrates caused by over-fertilization of agricultural lands in the drainage basin.

The authors also described three development activities that could diminish the protective ability of these zones: 1 ) river regulation to prevent flooding by isolating the river bed from its floodplain. This impoundment would reduce the water-logged area all along the stretch of the river; 2) land drainage that would lower the water table and reduce the duration of waterlogging in the riparian zone; and 3) deforestation of riparian forests that may lead to a decreased amount of organic carbon needed by bacteria in the denitrification reaction.

Redox Potential/Toxic Materials Accumulation (Box 8)

In estuarine and coastal marine ecosystems, we have described in the previous discussion how sediments may serve as a sink for toxic materials under conditions of low redox potential, and how they may serve as a source for the release of these materials under conditions of high redox potential. Also, we have seen how the dredging of anoxic, contaminated sediments, and disposal in aerobic environments may lead to remobilization of the sediment-bound toxic materials.

In certain freshwater systems containing sediments with toxic materials bound to iron and manganese oxides, the opposite behavior may prevail. The sediments are a sink for these materials under conditions of high redox potential, and a source of their release under conditions of low redox potential.

\subsection{Combined Primary and Secondary Interactions: Table 8}

Combining Tables 6 and 7 yields Table 8 . We may observe in the expanded matrix that in addition to the primary interactions identified earlier, several other development/environment interactions are revealed. Fossil fuel combustion is indirectly linked to the mobilization of heavy metals from terrestrial soils as a result of the acidification of the soils (Box 4).

Agricultural activities, in addition to the primary interactions, are also linked to several other effects through intermediate interactions. Soil and lake acidification may occur when wetlands with high concentrations of sulfide are drained for agricultural purposes (Box 5). Liming augments the ability of agricultural soils to adsorb certain heavy metals and pesticides, and conversely, the cessation of liming may 
Table 8. Development/Environment Interactions ${ }^{a}$ : Combined Primary and Secondary Interactions

a Text under double lines describes secondary interactions

\begin{tabular}{|c|c|c|c|c|}
\hline Consequences & Buffering Capacity & $\begin{array}{l}\text { Sorption Capacity } \\
\text { (Agricultural Soils) }\end{array}$ & Redox Potential & $\begin{array}{l}\text { Toxic Materials } \\
\text { Accumulation }\end{array}$ \\
\hline \multirow[t]{2}{*}{ Energy Use } & \multirow[t]{2}{*}{$\begin{array}{l}1 \\
\text { Acid deposition }\end{array}$} & \multirow[t]{2}{*}{2} & \multirow[t]{2}{*}{3} & $\begin{array}{l}1 \\
\text { Heavy metals;PAHs }\end{array}$ \\
\hline & & & & $\begin{array}{l}\text { Increased leaching of } \\
\text { metals from terrestrial } \\
\text { ecosysterns as a result } \\
\text { of acidification of soils }\end{array}$ \\
\hline \multirow{3}{*}{$\begin{array}{l}\text { Agricultural } \\
\text { Activities }\end{array}$} & $\begin{array}{l}5 \\
\text { Liming } \\
\end{array}$ & \multirow{2}{*}{$\begin{array}{l}6 \\
\text { Phosphate } \\
\text { application;cadmium, } \\
\text { other heavy metals, } \\
\text { pesticides }\end{array}$} & \multirow{2}{*}{$\begin{array}{l}7 \\
\text { Over-Fertilization } \\
\text { by nitrate, } \\
\text { subsequent discharge } \\
\text { to water } \\
\end{array}$} & $\begin{array}{l}8 \\
\text { Pesticide runoff }\end{array}$ \\
\hline & \multirow{2}{*}{$\begin{array}{l}\text { Drainage of } \\
\text { wetlands; } \\
\text { production of } \\
\text { of sulfuric acid }\end{array}$} & & & \multirow{2}{*}{$\begin{array}{l}\text { Accumulation of heavy } \\
\text { metals in sediments } \\
\text { under low redox } \\
\text { conditions caused by } \\
\text { nitrates leaching to } \\
\text { water bodies }\end{array}$} \\
\hline & & $\begin{array}{l}\text { Liming augments } \\
\text { sorption capacities; } \\
\text { cessstion of liming } \\
\text { will diminish them }\end{array}$ & $\begin{array}{l}\text { Disturbance of submerged } \\
\text { riparian woods } \\
\text { as sink } \\
\text { for nitrates }\end{array}$ & \\
\hline \multirow[t]{2}{*}{$\begin{array}{l}\text { Industrial } \\
\text { Activities }\end{array}$} & \multirow[t]{2}{*}{9} & \multirow[t]{2}{*}{10} & \multirow{2}{*}{$\begin{array}{l}11 \\
\text { Discharge to water } \\
\text { of organic carbon } \\
\text { chemicals with } \\
\text { high COD }\end{array}$} & $\begin{array}{l}12 \\
\text { Heavy metals;toxic } \\
\text { organic chemicals }\end{array}$ \\
\hline & & & & $\begin{array}{l}\text { Accumulation of heavy } \\
\text { metals in sediments } \\
\text { under low redox } \\
\text { conditions caused } \\
\text { by discharge of } \\
\text { chemicals with } \\
\text { high COD }\end{array}$ \\
\hline \multirow[t]{2}{*}{$\begin{array}{l}\text { Commercial and } \\
\text { Domestic Activities }\end{array}$} & \multirow[t]{2}{*}{13} & \multirow[t]{2}{*}{14} & \multirow[t]{2}{*}{$\begin{array}{l}15 \\
\text { Discharge to water of } \\
\text { organic carbon chemicals } \\
\text { with high COD }\end{array}$} & $\begin{array}{l}16 \\
\text { Heavy metals; toxic } \\
\text { organic chemicals }\end{array}$ \\
\hline & & & & $\begin{array}{l}\text { Accumulation of heavy } \\
\text { metals in sediments under } \\
\text { low redox conditions } \\
\text { caused by discharge of } \\
\text { chemicals with high COD }\end{array}$ \\
\hline
\end{tabular}


cause the adsorption reservoirs in soils to shrink (Box 6). River impoundment, land drainage, or deforestation of riparian wetland zones may cause increased nitrate discharges to rivers (Box 7). Current practices of over-fertilization affect the accumulation of toxic metals in estuarine and marine sediments by contributing to the low redox potential that favors accumulation (Box 8).

Similarly, industrial, commercial, and domestic activities, in addition to directly generating toxic materials, also affect the accumulation of toxic chemicals in aquatic sediments by influencing the redox conditions of the waters above these sediments (Boxes 12 and 16). They do so by directly discharging into these water bodies, large quantities of organic wastes with high CODs.

\subsection{The Potential Impact of Climatic Change}

In addition to Table 8 , it is also instructive to consider the effect that global climatic change could have on the CEIs. I treat climate in this section as an exogenous factor affecting Europe, although European activities that generate "greenhouse gases" certainly contribute in part to climatic change.

Of the CEIs considered in this report, the possible direct effect of climatic change on the redox potential of soils may be the most important. Earlier, I described how the redox potential was very much governed by the limited concentration of molecular oxygen in water. I cited two examples, the acidification of Lake Blamissusjon, and the nitrate trap provided by the water-logged riparian woods, to illustrate how the chemical response in soils could change dramatically, depending on whether they were water-logged or drained. The two cited examples were local occurrences, and in and of themselves, not very important on a continental scale. However, suppose in the future there were broad scale changes in the hydrological cycle in Europe such that wetlands dried out, and dry lands became wetter due to the lowering and raising of water tables in response to shifting seasonal and annual patterns of precipitation and evapotranspiration. And if these changes were accompanied by broad scale increases in the acidification of soils, there could be major shifts in soil chemistry, with potentially important impacts on the environment. Much has been written about the leaching of heavy metals from terrestrial soils as a result of acidification. However, as was shown in Figure 22, mobilization depends not only on $\mathrm{pH}$, but is equally affected by the redox potential.

It is beyond the scope of this paper to delve deeply into a discussion of future climatic change in Europe. Suffice it to say here that even though we cannot yet predict precisely how the climate in Europe may change in the next century, the best current models appear to lend credence to the possibility of wide-spread changes in European hydrology. Figure 25 shows the changes in summer soil moisture based on a model developed by Manabe and Wetherald (1986), assurning a dou- 
bling of the current $\mathrm{CO}_{2}$ levels. ${ }^{9}$ One may observe broad-scale reduced moisture levels for nearly the entire continent. Reductions in moisture of up to $50 \%$ were calculated for Southern Europe, and as much as $30 \%$
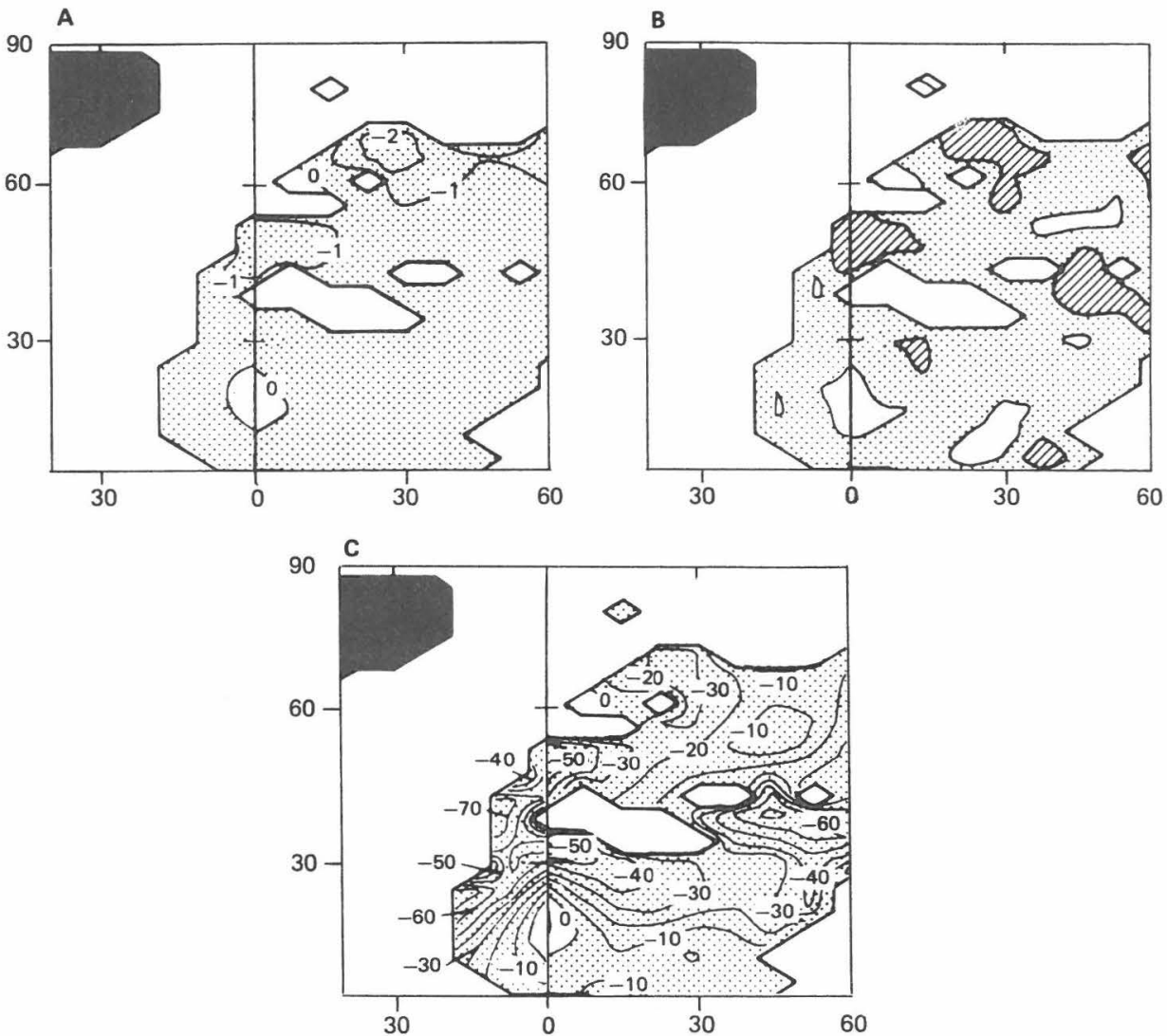

Figure 25 (a) Geographical distribution in Europe of the change in soil moisture (centimeters) in response to a doubling of $\mathrm{CO}_{2}$ for the period from June to August. Shading indicates regions where the $\mathrm{CO}_{2}$-induced change is negative. (b) Statistical significance of the $\mathrm{CO}_{2}$-induced change in soil moisture shown in (a). Areas shaded with lines are regions where the negative soil moisture change is statistically significant at the $10 \%$ level. (c) $\mathrm{CO}_{2}$ -induced change in soil moisture expressed as a percentage of soil moisture obtained from the normal $\mathrm{CO}_{2}$ experiment. Source: Manabe and Wetherald, 1986.

\footnotetext{
${ }^{9}$ According to current estimates, the equivalent of a doubling in $\mathrm{CO}_{2}$ could occur as early as about 2030. This assumption is based on a $50 \%$ rise in $\mathrm{CO}_{2}$ by that time, as well as an increase in the so-called "greenhouse" gases, that may contribute the equivalent of a $50 \%$ rise in $\mathrm{CO}_{2}$ by 2030 .
} 
in Northern Europe. Understanding the implications of such large regional reductions in soil moisture on the soil's redox potential could be of critical importance. Will large numbers of lakes acidify after the fashion of Lake Blamissusjon? Will nitrate levels discharging into rivers increase as riparian wetlands dry out? In planning a research agenda for long-term ecological substainability in Europe, these and related questions should be considered for more detailed investigation.

\section{IMPLICATIONS FOR ENVIRONMENTAL CHANGES IN THE FUTURE, INCLUDING SURPRISES}

One way to imagine how the environment may change in the future is to examine the activities that could, directly or indirectly, drive the changes (here described as changes in the CEIs), and to ask how those activities might evolve in the future. Table 8 was constructed in order to facilitate that task. Another approach might be to start from the impact end of the assessment. Here one asks: within which environmental settings are changes in the CEIs most likely? Then, working backwards, asks whether these environmental settings are possible, and if so, under which activities or circumstances could they be realized? Both approaches are used here interactively .

I describe below, six potential environmental changes. These are based on the information in Table 8, considerations about the effects of climate change, the analyses conducted in the previous sections of this paper, and finally, by simply thinking about the sensitivities of particular CEIs. The first three listed are changes induced by primary (direct) interactions between chemical inputs and ecological systems, and the last three are from secondary (indirect) interactions. Because some of the changes occur within a background of improving environmental conditions, they may appear as surprising, or perhaps even paradoxical at first glance, but are actually quite understandable in the context of the linkages described in the previous sections. Since I have already discussed these changes in some detail, I will not elaborate upon them further. For more specific information the reader may refer to the relevant sections.

\subsection{The Continued Acidification of Soils, Even in an Era of Reduced Acidic Emissions}

According to the analysis of Alcamo et al. (1987), current planned reductions of emissions of $S_{x}$ in Europe by $30 \%$ relative to 1980 values will not be sufficient to prevent wide-scale and continuing acidification of forest soils in Central Europe by the year 2040. As shown in Figure 6 , as much as $60 \%$ of the soils could have pHs less than 4 by that time. These levels of $\mathrm{pH}$ are in the range of the buffering capacity of alumi. num, and hence could result in its broad-scale leaching from these soils. The problem is that although the reductions will certainly slow down acidification, the depletion of buffering capacities will still occur at 
rates more rapid than the rates at which soils can replenish their capacities. The situation will be aggravated by emissions of $N O_{x}$, whose contribution to the total acidity will continue to increase in the future.

\subsection{The Saturation of Soils by Phosphate, and Subsequent Leaching of Phosphates into Ground and Surface Waters, Leading to a New Wave of Eutrophication of European Water Bodies}

Currently in the Netherlands in areas of enormous livestock feedlots, phosphate saturation has already occurred where large excesses of livestock manure have been applied in sandy soils of adjacent farms. In other areas of Europe phosphate inputs, though not as large as in the Dutch example, are nonetheless substantial, and about half the phosphorous applied appears to be stored in the soils. Calculations by Behrendt (1988) show that over the next 90 years 1 to 2 meters of agricultural soils could be completely saturated, and leaching may occur in areas with high water tables. (See Figure 12.)

A major problem with phosphorus is that no natural process comparable to "nitrogen-fixation" exists. Hence, the possibility for a technological breakthrough in improving the efficiency of plants for phosphorus uptake will not be available in the foreseeable future. Accumulations may be slowed significantly, however, if official recommendations of agricultural extension services are adopted. Then the application level is adjusted on the basis of phosphorus availability in the soil. This practice would entail, however, regular soil-sampling analysis on the farm level.

\subsection{A Continuation of Anoxic Conditions in Coastal Waters, Resulting in Episodic Fish-Kills and Emissions of Hydro- gen Sulfide}

As demonstrated in Figure 18, by the early 1980s unprecedented episodes of fish kills and $\mathrm{H}_{2} \mathrm{~S}$ generation were observed off the Danish coast. The same phenomenon has been observed in the Gulf of Saronik near Athens. It is possible that similar episodes may spread to other regions of Europe in the future. This may occur even after a significant improvement in sewage treatment. In fact the percentage of the population of Denmark served by waste-water treatment plants increased from just over $50 \%$ in 1970 , to about $90 \%$ in 1983 . Unlike the episode off the Greek coast, which was the result of the discharge of sewage wastes, the Danish episode was caused by large discharges of nitrate fertilizers into the coastal areas. Since the major rivers emptying into the North Sea contain nitrate levels 30 to 40 times higher than background levels, there will have to be significant reductions in the runoff

10 Greece is exceptional in that as of 1980 hardly any of the population was served by sewage treatment. For most of the OECD countries there has been a considerable increase in sewage treatment since 1970 (OECD, 1985). 
of fertilizers in the future in order to prevent anoxia in the coastal waters. The southern and eastern areas of Europe may be particularly vulnerable in this regard, since in many of these areas agricultural activities are still expanding. (In western Europe they have peaked and may decline sharply in the future.)

Furthermore, tourism along the Mediterranean and Adriatic coasts has increased markedly in recent years. The sea-side towns in these areas often do not have adequate sewage systems to treat the huge increases of wastes caused by increased populations during the summer months.

\subsection{The "Bleeding" of Toxic Metals from Contaminated Estuarine Sediments in an Era of Vastly Improved Water Quality}

The previous discussion indicated that in terms of accumulations of toxic materials in the sediments of estuaries, and coastal areas (and conversely the potential for release from these sediments), the status of the redox conditions in the overlying water columns will be at least as important a factor as are the direct accumulated inputs of pollutants.

If current trends continue in Western Europe, there will be major reductions in organic carbon inputs to the large river systems. Virtually all the countries in this region have vastly expanded their capacities for waste water treatment in the last two decades (OECD, 1985). Also, at least for some of the heavy metals such as mercury and cadmium, there seem to have been significant reductions over the last decade in direct discharges into major rivers such as the Rhine (OECD, 1985). However, because of the huge excesses of nitrogen fertilizers still discharging into these rivers, the low redox conditions still prevail. If solutions are found for reducing water pollution from nitrate, there should be a significant improvement in water quality in Western Europe. Possible significant reductions may occur as a result of the following: better, more efficient methods for nitrogen fertilizer application (see, for example, Fleischer et al., 1987); the discovery, through biotechnological research, of nitrogen-fixing cereals; the large-scale cut-back of agricultural activity due to overproduction in the EC countries.

If the quality of these waters were to improve significantly, the new environment would be a combination of clean waters overlying heavily contaminated sediments. We have noted in the previous discussion that under these conditions the sediments could be a source of, rather than a sink for toxic chemicals. (See Figure 20 and the ensuing discussion.) Preliminary studies indicate that the sediments in these conditions will purge themselves by releasing metals at various rates, possibly for many years into the future. Furthermore, a significant fraction of the remobilized metals may be in a form far more available to biota than the form under which they were first deposited into the sediments.

The above discussion is not to suggest that we should avoid 
ing polluted water courses. Rather, in making management decisions about clean-up programs, it is very important that the decision maker uses available knowledge to understand at least some of the contingencies, surprises, trade-offs, and risks inherent in the final plan of action. Only then will such decisions be informed, and the quality of thinking among the decision makers maximized. For example, perhaps the most robust decision would be to set up, as a concurrent activity to the clean-up, a system for monitoring toxic metal concentrations in selected water bodies in order to seek answers to important questions such as the degree of bioaccumulation, the potential impacts on human health, and the hydrological and physiochemical conditions under which the effects of toxic releases from these sediments would be most detrimental.

\subsection{The Release of Toxic Metals from Agricultural Soils Upon the Cessation of Liming}

We have demonstrated that liming of soils may serve to amplify the soil's capacity to adsorb heavy metals. It is possible, perhaps even likely, that in the coming decades large tracts of agricultural land in Europe will be abandoned for agricultural purposes, and liming discontinued. With the exception of acid deposition, liming is probably the major anthropogenic activity affecting soil $\mathrm{pH}$. When soils are no longer limed, there could be a significant, and rapid decrease in $\mathrm{pH}$. This effect will be aggravated in areas receiving high levels of acid deposition. Because some of these soils have been the recipient of cumulative doses of heavy metals and pesticides over several decades, the sudden decline in $\mathrm{pH}$ may cause large discharges of these metals into ground and surface waters. Such events could trigger serious ecological and human health problems. Given that agricultural lands, at least in Western Europe, could be decreased by $20 \%$ or more, the effects could be widespread on a regional basis.

\subsection{Environmental Changes Occurring as a Result of Changes in Soils' Redox Conditions Due to Drying Up of Wetlands, or the Moisturization of Dry Lands}

We have seen in the development of our matrix (Table 8), an example in a region of northern Sweden whereby drainage of watershed soils high in sulfide minerals caused the severe acidification of a lake and its drainage basin. The cause of this event was the exposure of the sulfide minerals to atmospheric oxygen, resulting in the oxidation of sulfide to sulfuric acid.

We have also noted how the nitrogen cycle can be significantly affected by wetland areas, which may serve as nitrate traps, thus buffering rivers from high inputs of nitrate from agricultural lands in the drainage basin. There are no doubt many other examples of how changing redox conditions in the soils may influence the quality of soils and surface waters. The two cases cited here are merely by way of example. 
Moreover, redox conditions in the soil strongly influence the emissions of trace gases to the atmosphere (G. Zavarzin, Institute of Microbiology, U.S.S.R. Academy of Sciences, Puzchino, personal communication, 1986; Mooney et al., 1987). For example, water-logged soils may emit significant quantities of $\mathrm{N}_{2} \mathrm{O}$ and methane, which are trace gases that have an important influence on global climate.

Given that there may be large changes in the hydrological conditions in Europe in the next century caused by global climate change, there may also be broad-scale changes in redox conditions in the soils as water tables rise or fall. Falling water tables will change the soil chemistry from one governed by reducing conditions to one governed by oxidizing conditions in some of the areas now submerged or waterlogged . Conversely, rising water tables will change the soil chemistry from one dominated by oxidizing conditions to one dominated by reducing conditions in some areas now dry.

From our two examples, we know that under certain circumstances lowering of the water table could cause lake acidification and increased runoff of nitrates into rivers. Would there be another wave of acidification under the new hydrology? A first step might be to overlay a current map of European soils high in sulfide minerals, or in stored sulfur from acid deposition, with maps showing possible changes in hydrology. Potentially vulnerable areas would be those showing reduced water availability in areas of high concentration of sulfide minerals. Will the drying up of wetlands in agricultural regions cause a new wave of nitrate pollution in water courses? Again a first step might be to overlay a current map of the wetlands of Europe, with maps of current agricultural activity and maps of possible new hydrologies.

Moreover, some bogs, peatlands, and other wetlands may have stored high inputs of toxic metals during previous decades. Drying of these areas would increase the redox potential, rendering certain metals more mobile. With subsequent rainstorms, these metals could be flushed from the wetland to downstream waters.

\section{IMPLICATIONS FOR A MONITORING STRATEGY}

One goal of this paper has been to demonstrate how activities of socio-economic development in the areas of energy use, agriculture, industry, and commercial and domestic consumption affect certain capacities of soils, waters, and sediments, and how the causal activities may be displaced in time and space from the manifestation of environmental effects. As noted earlier, Brooks (1986) has cautioned that the ultimate danger of such a relationship is that the activities, for which societies generally reap rapid short-term gratification and economic benefit, tend to become entrenched over time, making it difficult for adjustment or change by the time the disbenefits become known. Moreover, even if adjustments can be made willingly, it may be too late if the particular degradation is not reversible. 
Another goal implicit in the analyses presented in this paper is the question of our obligations to future generations for the responsible stewardship of the environment. (See for example Brown Weiss, 1984.) Most of the examples presented in the previous sections might be described as environmental "time bombs." The explosion may occur in the generation of our grandchildren, but the ticking of the clock has begun in our generation, as we contribute to the year by year accumulations that will lead eventually to rapid threshold responses.

One of the major needs of long-term strategic planning for the ecological sustainability of Europe is a monitoring system for early warning of potential environmental threats. By early warning I mean identification of a problem early enough to allow sufficient time for society to mobilize an effective response. I offer here a few ideas that hopefully will help toward that goal.

\subsection{Indicators: Inputs and Capacities of Reservoirs}

The first step in designing such a system is to define a set of indicators that will provide reliable early warning of potential environmental changes. As an example, we may again refer to the previous discussion on the acidification of Big Moose Lake. (See Figure 3 and the ensuing discussion.) What would have been an appropriate monitoring strategy, implemented say in the year 1920, to have foreseen the acidification of the lake that was to occur around 1950? Certainly, measuring the $\mathrm{pH}$ of the lake alone, or even the $\mathrm{pH}$, the sulfur emissions up-wind from the lake, and the fish species populations would have been insufficient to have foreseen the acidification. The key indicator was the buffering capacity of the watershed soil. That was the slow variable whose depletion over the decades since 1880 was occurring as a result of cumulative alterations of base cation supply that would appear as minor if viewed over a short time horizon. In fact, it was the only indicator between 1920 and 1950, for which a significant change would have been observed. Emissions of sulfur were nearly constant over this period, as were the $\mathrm{pH}$ of the lake and the fish species populations. By the time changes in $\mathrm{pH}$ and fish populations were observed, it would have been too late to reverse the effect.

From this example we can clearly understand the overriding importance of knowing precisely what to measure when designing an effective monitoring program. As shown in Figure 26a, for an ecological change that is delayed in time with respect to the source of change, there is generally no direct linkage between cause and effect. Rather, the source of pollution acts on the environment through some intermediate step. Moreover, this step must generally involve a depletion of some capacity through an accumulation of some pollutant. It is this depletion that appears as a slowly changing variable in time, and it is this variable which must be monitored.

As illustrated in Figure 26b, in more complex cases there may not only be one, but two or several intermediate steps. In this situation, it 


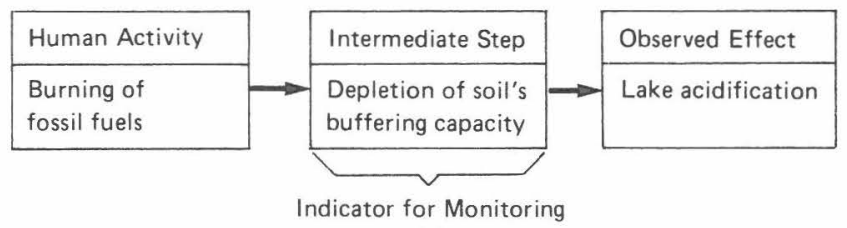

(a)

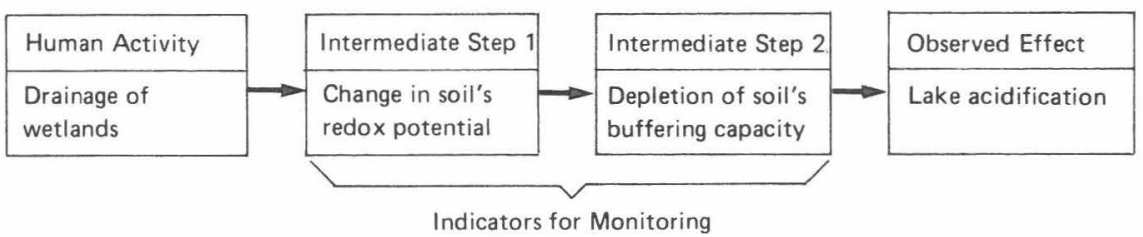

(b)

Figure 26 (a) Illustration of simple linkage between human activity (cause), and the observed effect for the case of acid deposition and lake acidification. (b) Illustration of more complex linkage for the case of drainage of wetlands and lake acidification.

will be crucial to monitor the rate-determining step, and to have information about the linkages between all the intermediate steps. In the example shown in Figure 26b, monitoring the depletion in buffering capacity of the soil may provide warning of the impending acidification of the lake in the watershed, but we would not be able to connect the depletion of buffering capacity to land drainage, unless we knew the linkages between land drainage, changing redox potential, and soil acidification.

A soil or sediment system that accumulates pollutants may be viewed as a reservoir from which pollutants begin to leak as the capacity for accumulation becomes saturated over time. Alternatively, leakage may occur owing to a sudden shrinkage of an ecological reservoir. In this case pollutants may leak even after their inputs to the ecosystem have ceased. In order to effectively monitor such systems, it is necessary to understand the chemical factors regulating the size of the reservoir. For example, for heavy metals present in agricultural soils, $\mathrm{pH}$ is a major factor; for heavy metals in marine and estuarine sediments, the redox potential in the overlying water is a major factor. (See Figures 15 and 20.)

In light of the above discussion, a monitoring program that will effectively provide early warning of the release of deleterious chemicals from soils and sediments to the environment should include the follwing three considerations:

1. In the case of slow accumulations and storage of pollutants in an environmental system, the size of the system's reservoir and the inputs of pollutants over time should be determined. 
Quantification of these parameters is required in order to predict the time scale over which the system may become saturated.

2. There must be a mechanistic linkage established between the source of pollution, the measured indicator, and the final effect. For multi-step processes involving several intermediate linkages, the coupling between the indicator and the other intermediate processes must be understood.

3. In the case in which an ecosystem's storage capacity for a given pollutant may shrink suddenly owing to a change in certain chemical conditions (e.g., pH, redox potential), it is necessary to monitor these conditions through measurement of the appropriate chemical parameters. This activity should be coupled with the monitoring of the input pollutant.

\subsection{Lessons from the Most Vulnerable Areas}

In designing a program that will provide early warning of sudden ecological changes, one logical place to start looking for such changes is in the most vulnerable areas. As we have seen, two factors determine vulnerability: 1) the level of inputs of polluting chemicals; and 2) the size of the reservoir accumulating them.

The history of the acidification of European soils and waters demonstrates both the potential utility of this approach, and the lost opportunity in foreseeing the spread of acid deposition from initially a very small region in Southern Scandinavia to most of the central part of Europe. Central Europe experiences the highest inputs of acid, although its soils have been fairly resistant to acidification. Southern Scandinavia has experienced more moderate inputs of acidification, most of it imported from up-wind sources in the U.K., Germany and elsewhere. However, its soils possess among the lowest buffering capacities on the continent. Hence, according to the two criteria given above, both Southern Scandinavia and Central Europe were prime candidates for vulnerability to acid deposition. As shown in Figure 27, the direct effects of acidification were first observed in Scandinavia. The earliest signs appeared in the 1920 s when reduced stocks of salmon were observed in rivers in southern Norway that were previously prolific fishing rivers. It wasn't until decades later that direct effects were observed in Central Europe.

The experience in Scandinavia could have provided warning of what would inevitably happen in Central Europe had the early signs been heeded. Indeed, as has been pointed out by Paces (1985), mounting evidence within Central Europe of deleterious effects from acid deposition was largely ignored:

Nobody worried about acidification. The term was unknown. The first practical acknowledgment of the problem came when farmers began to place lime on their fields. This process was in most cases sufficient to neutralize agricultural acidification. 
Ten years ago, after about 150 years of acidification, we in central Europe were still concerned with the eutrophication of lakes and rivers and not with acidification. We did not observe any remarkable systematic decrease in the $\mathrm{pH}$ of surface waters except in some high-altitude lakes. We measured a systematic increase in sulfate and nitrate in runoff and noted that topsoil was losing humic substances. In trees we observed the spread of parasitic disease and increasing damage caused by winds and snowfall. Still nobody seemed to be concerned with acidification.

Meanwhile, in Scandinavia, where atmospheric acid pollution is only a small fraction of that found in central Europe, scientists became seriously concerned with this problem upon discovering drastic decreases in the fish populations of acid lakes. The problem was perceived as an international one because much of the acidic input was produced outside Scandinavia's frontiers. Nevertheless, acidification was not much of an issue during the 1972 United Nations Environment Conference in Stockholm.

One lesson to be learned from this experience is that perhaps, as a general principle, we should pay closer attention to what appear to be novel environmental occurrences on a local scale, but which may in fact be harbingers of future problems on a grander scale. If these events are good natural experiments or test cases for what is to come, then perhaps we should find out why the effect appeared at the particular location, and try to discern whether the episode is indeed only of local significance, or whether the same event could happen elsewhere under changing conditions. In this paper, we have noted that in recent years, extraordinarily high levels of phosphate have been applied to soils of local farms in the livestock feeding areas of the Netherlands. The inputs are so high that these soils are already experiencing saturation of phosphate sorption capacities. We suggested that the same problem could occur in other parts of Europe, where, although levels of application may not be as high, accumulations over longer periods of time could lead to the same deleterious effects.

One specific recommendation would be to develop a European-wide vulnerability map for phosphate sorption capacities. Dutch investigators have already developed a method for obtaining an index of vulnerability utilizing information readily obtained from standard soil maps (Schoumans et al., 1987). Such a map could be overlayed by other maps showing the intensity of phosphate application and the depth of water tables, in order to determine the location of the most vulnerable areas. Regular monitoring of the soils in those areas could provide a valuable assessment of the timescale over which effects may be manifested. This information could then be used more widely to assess the magnitude of the problem in other, less vulnerable areas of the continent, and perhaps to foresee problems in the future, given certain scenarios of development. 


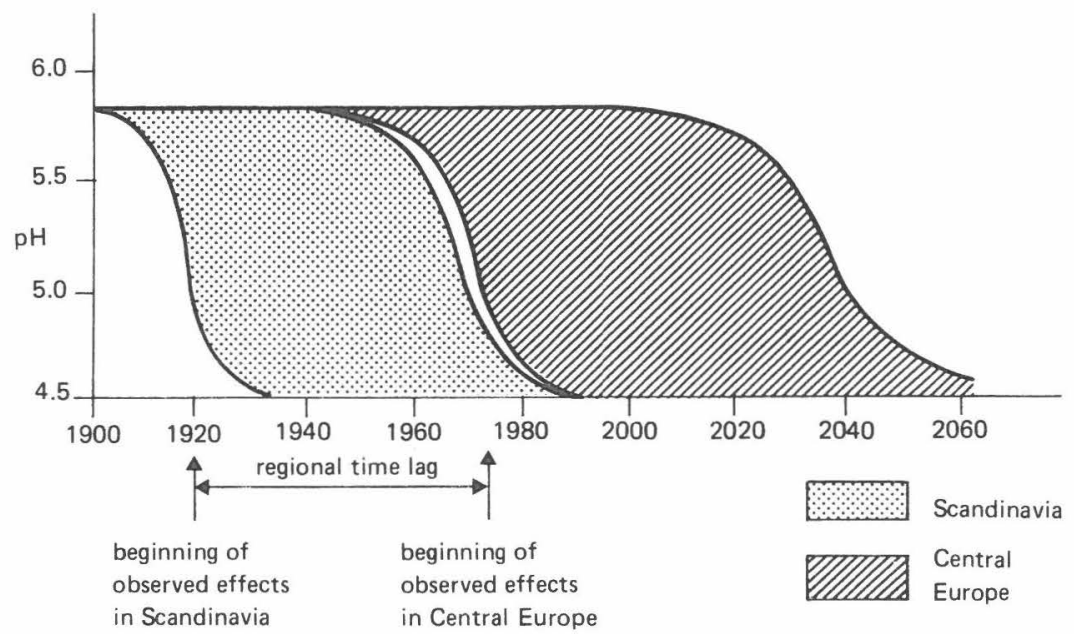

Figure 27 Time horizons of effect of acid deposition on acidifications of soils and lakes in Scandinavia and Central Europe, indicating the lag time in response of Central European soils of about 50 years relative to the response of Scandinavian soils. Central Europe includes West Germany, Switzerland, Austria, Hungary, Czechoslovakia, Poland, and East Germany.

Another area of focus should be the estuaries and coastal areas of Europe. We have already observed that the North Sea and adjacent inland areas, fed by rivers transporting pollutants from some of the most heavily industrialized and intensively cropped areas in the world, have become major sinks for toxic wastes, and worrisome ecological changes have already been observed. The trends in other coastal regions of Europe should be investigated. Are they prone to similar degradation if they follow a similar development path? Can we use the knowledge gained from the analysis of the circumstances causing the fish kills off the Danish coast in the early 1980s to foresee how and where similar events could be repeated? Is the Adriatic coast similarly threatened, especially in summer by large discharges of untreated sewage wastes caused on the one hand by the ever-increasing flow of summer vacationers to coastal towns, and on the other by sewage treatment facilities totally inadequate to service the expanded summertime populations?

\subsection{The Bottom-up Approach}

It is not always possible to uncover vulnerabilities by looking to areas with high inputs of pollutants, or areas that are particularly pollutant-sensitive. This is especially true when attempting to anticipate problems that do not currently exist. In these cases the "bottomup" approach might be particularly useful. Here, the focus is on the impact, and the analyst asks two questions: 1) To what factors is the impact particularly sensitive? and 2) Under what scenarios could these 
factors change in the future? Figure 28 illustrates how the method might be applied to the critical environmental indicators highlighted in this report.

The five listed "sensitive" factors and the scenarios under which these factors could change are based on the discussions in the previous sections. The redox conditions in the soils and wetlands of Europe could change markedly owing to alterations in moisture conditions due to climatic change. The release of heavy metals in contaminated sediments of estuaries and coastal areas is sensitive to two factors: 1) the redox conditions in the overlying waters; and 2) the mechanical disturbance of the sediments. It is possible that both factors will gain in importance in the future, as water quality generally improves, and as sea level rise and the increased frequency of storms causes increased turbulence in the sediments of the coastal and estuarine areas. We have seen that sorption capacities are very sensitive to acidity, and acidity may increase in the future in soils of abandoned farm land if the practice of liming these soils is halted. Finally, acid deposition itself, the distribution of which is dependent on patterns of rainfall and wind direction, may also be affected by climate change if these patterns change markedly.

The advantage of the "bottom-up" approach is that it raises questions that might otherwise not have occurred to the experts studying the various environmental problems from the "top-down." In so doing, it may help to channel some of the ongoing research and monitoring programs in climatic change, water quality, and agricultural pollution in a direction that is more directly applicable to long-term impacts on the critical environmental indicators.

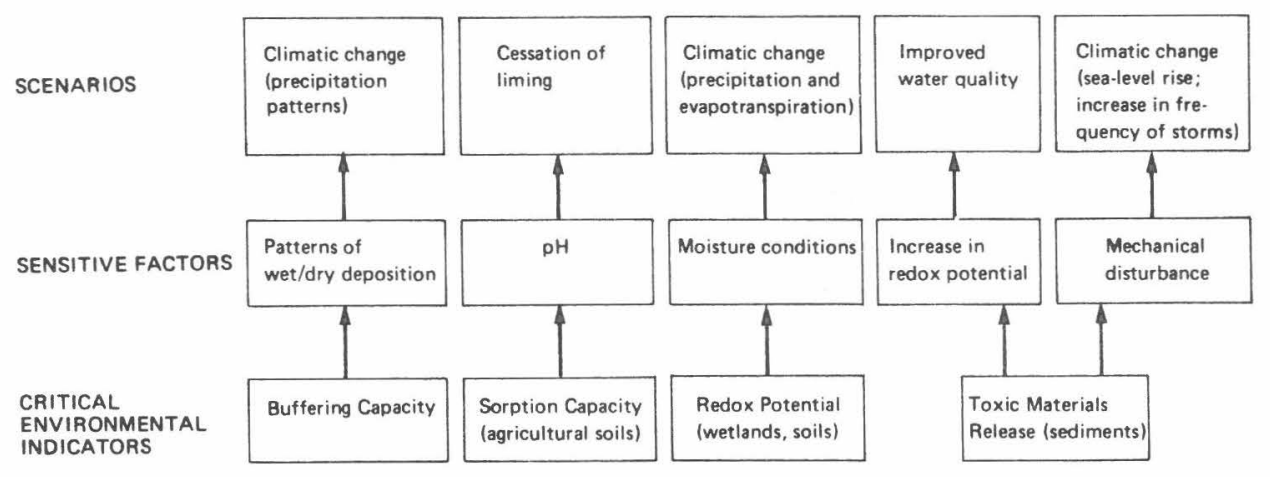

Figure 28 Illustration of the bottom-up approach. 


\section{CONCLUSION}

Over the last 15 years or so, industrial societies have become acutely aware of the problems caused by the method of disposal of toxic chemical wastes favored in previous decades; viz., containment of the chemicals in metal drums and burial at prearranged dump sites. The problem of course is that metal drums corrode over time and eventually leak, causing the toxic chemicals to be released to the wider environment. Analogously, the accumulation and storage of deleterious chemicals in the natural environment has the same potential for "leakage" into vulnerable ecosystems or habitats. The leaks in this case are not caused by corrosion of metal containers, but rather, by the saturation of a storage capacity, or by a sudden shrinking of a storage capacity owing to rapid changes in the chemical conditions that regulate its size. Examples of saturation given in this paper are: 1)the depletion of soils' buffering capacities from high inputs of acid deposition; 2) the depletion of phosphate sorption capacities from cumulative additions of phosphate fertilizers; and 3) the exhaustion of oxygen in marine waters from high inputs of carbon or nitrogen nutrients. Examples of shrinkage of capacities are: 1) the leaching of toxic metals from agricultural soils after the cessation of liming; 2) the release of toxic materials from polluted sediments owing to changing redox conditions in overlying water bodies; and 3 ) the release of sulfates from wetlands under drying conditions.

Clearly, the three capacities discussed in this paper determine the retention and release of numerous chemicals in the natural environment, and specify the timescales over which deleterious ecological effects may occur. Hence strategies for preventing the long-term release of such materials must consider these capacities, and how they may shrink or expand in the future.

\section{ACKNOWLEDGMENT}

The author is indebted to Professor Roland Wollast of the Université Libre de Bruxelles for useful discussions in the initial conceptualization of this paper.

\section{REFERENCES}

Alcamo, J., M. Amann, J.-P. Hettelingh, M. Holmberg, L. Hordijk, J. Kamari, L. Kauppi, P. Kauppi, G. Kornai, and A. Makela. 1987. Acidification in Europe: a simulation model for evaluating control strategies. Ambio 16: 232-245.

Almer, B., W. Dickson, C. Ekstrom, and E. Hornstrom. 1978. Sulfur Pollution and the Aquatic Ecosystem. In: Sulfur in the Environment, Part 2, J. Nriagu (ed.). New York: John Wiley and Sons. 
Andersson, F. 1986. Acidic deposition and its effects on the forests of nordic Europe. Water, Air and Soil Pollution 30:17-29.

Bayley, S.E., R.S. Behr, and C.A. Kelly. 1986. Retention and release of S from a freshwater wetland. Water, Air, and Soil Pollution, 31:101 - 114.

Beanlands, G.E. and P.N. Duinker. 1983. An Ecological Framework for Environmental Impact Assessment in Canada. Institute for Environmental Studies of Dalhousie University, Halifax; and Federal Environmental Assessment Review Office, Hull, Quebec.

Behrendt, H. 1988. Changes in nonpoint nutrient loading into European freshwaters: trends and consequences since 1950 and not-impossible changes until 2080. Report no. WP-88-000. Laxenburg, Austria: International Institute for Applied Systems Analysis.

Berman, M. and R. Bartha. 1986. Control of the methylation process in a mercurypolluted aquatic sediment. Environmental Pollution (Series B) 11: 41-53.

Bjoernberg, A., L. Hakanson, and K. Lundbergh. 1988. A theory on the mechanisms regulating the bioavailability of mercury in natural waters. Environmental Pollution 49: 53-61.

Braekke, F.H. 1981. Hydrochemistry of high altitude catchments in South Norway. 1. Effects of summer droughts and soil-vegetation characteristics. Rep. Norw. For. Res. Inst. 36.8,26pp.

Braekke, F.H. Ed. 1976. Impact of Acid Precipitation on Forest and Freshwater Ecosystems in Norway. SNSF-Projekt, Research Rept. 6/76, 1432 Aas, Norway.

Breeuwsma, A. and O.F. Schoumans. 1987. Forecasting Phosphate Leaching from Soils on a Regional Scale, pp: 973-982. In: Vulnerability of Soils and Groundwater to Pollutants; International Conference, Noordwijk aan Zee, The Netherlands, March 30 April 3, 1987. The Hague: National Institute of Public Health and Environmental Hygiene.

Brooks, H. 1986. The Typologies of Surprises in Technology, Institutions, and Development, chapter 11, pp: 325 - 348. In: Sustainable Development of the Biosphere, W.C. Clark and R.E. Munn (eds.). Cambridge: Cambridge University Press.

Brown, K.A. 1980. The Distribution of Sulfur Compounds in a Peat Bog in Relation to Stream Water Chemistry. Report of Central Electricity Research Laboratories, RD/L/N 150/80. Central Electricity Generating Board. Surrey, England, 18pp.

Brown Weiss, E. 1984. The planetary trust: conservation and intergenerational equity. Ecology Law Quarterly 11: 495-581.

Brugam, R.B. and M. Lusk. 1986. In: Diatoms and Lake Acidity, pp: 115-129, J.P. Smol, R.W. Battarbee, R.B. Davis, and J. Merilainsen (eds.). Dordrecht, The Netherlands: Junk.

Calles, U.M. 1983. Dissolved inorganic substances. A study of mass balance in three small drainage basins. Hydrobiologia 101:13 - 18.

Charles, D.F. and S.A. Norton. 1986. Paleolimnological Evidence for Trends in Atmospheric Deposition of Acids and Metals., chapter 9, pp: 335-431. In: Acid Deposition Long-Term Trends, National Research Council. Washington, DC: National Academy Press.

Chemical and Engineering News. 1987, vol. 65, no. 41 (October 12), pp: 14-15. Hazardous waste found in household garbage. (Summary of a report of the U.S. Environmental Protection Agency.)

Chen, K.Y., S.K. Gupta, A.Z. Sycip, J.C.S. Lu, M. Knezevic, and W.-W. Choi. 1976. Research Study on the Effect of Dispersion, Settling, and Resedimentation on Migration of Chemical Constituents during Open-Water Disposal of Dredged Materials. U.S. Army Engineer Waterways Experiment Station, Contract Rep. D-76-1, CE, Vicksburg, Miss. 
Clark, W.C., 1986a. Editorial. Environment 28, no.10 (December).

Clark, W.C. 1986b. Sustainable Development of the Biosphere: Themes for a Research Program, chapter 1, pp: 5-48. In: Sustainable Development of the Biosphere, W.C. Clark and R.E. Munn (eds.). Cambridge: Cambridge University Press.

Compeau, G. and R. Bartha. 1984. Methylation and demethylation of mercury under controlled redox, $\mathrm{pH}$, and salinity conditions. Applied and Environmental Microbiology 48: 1203-1207.

Crutzen, P.J. and T.E. Graedel. 1986. The Role of Atmospheric Chemistry in Environment-Development Interactions, chapter 8, pp: 213 - 249. In: Sustainable Development of the Biosphere, W.C. Clark and R.E. Munn (eds.). Cambridge: Cambridge University Press.

DeGroot, A.J. 1977. Assessment of Certain European Dredging Practices and Dredged Material Containment and Reclamation Methods. Appendix E: Heavy Metals in the Dutch Delta, an Integrated Program for Research. Final Report, Contract DAJA 37-75-C-0382, U.S. Army Engineer Waterways Experiment Station, CE, Vicksburg, Miss.

DeHaan, F.A.M. 1987. Effects of Agricultural Practices on the Physical, Chemical and Biological Properties of Soils: Part III--Chemical Degradation of Soil as a Result of the Use of Mineral Fertilizers and Pesticides: Aspects of Soil Quality Evaluation, pp: 211-236. In: Scientific Basis for Soil Protection in the European Community, H. Barth and P.L. L'Hermite (eds.). London: Elsevier Applied Science.

DeVries, W. and A. Breeuwsma. 1986. Relative importance of natural and anthropogenic proton sources in soils in the Netherlands. Water, Air, and Soil Pollution 28:173-184

DeWit, C.T. 1981. Oude wijn in nieuwe zakken. Landbouwkundig Tijdschrift 99:257-62.

Dickson, W. 1980. Properties of acidified waters, pp: 75-83. In:Ecological Impact of Acid Precipitation; Proc. of an International Conference, Sandefjord, Norway, March 1114, 1980. Oslo: SNSF Project.

Dillon, P.J., R.A. Reid, and E. de Grosbois. 1987. The rate of acidification of aquatic ecosystems in Ontario, Canada. Nature 239: 45-48.

Fleischer, S. and S. Hamrin. 1987. Land use and nitrogen losses - a study within the Laholm Bay drainage basin of southwest Sweden. Verh. Internat. Verein Limnol. 29 (in press).

Fleischer, S., S. Hamrin, T. Kindt, L. Rydberg, and L. Stibe. 1987. Coastal eutrophication in Sweden: reducing nitrogen in land runoff. A mbio 16: 246-251.

Foerstner, U. 1986 (in press). Changes in Metal Mobilities in Aquatic and Terrestrial Cycles. In: Proceeding of the International Seminar on "Speciation, Separation and Recovery of Metals", J.W. Patterson (ed.). Chelsea, Mich., U.S.A.: Lewis Publishers.

Foerstner, U. 1980. Cadmium in Polluted Sediments, chapter 9, pp: 305-363. In: Cadmium in the Environment, J.O. Nriagu (ed.). New York: John Wiley \& Sons.

Gambrell, R.P., R.A. Khalid, and W.H. Patrick, Jr. 1980. Chemical availability of mercury, lead, and zinc in Mobile Bay sediment suspensions as affected by $\mathrm{pH}$ and oxidation-reduction conditions. Environmental Science and Technology 14: 431-436.

Gambrell, R.P., R.A. Khalid, M.G. Verloo, and W.H. Patrick, Jr. 1977. Transformations of Heavy Metals and Plant Nutrients in Dredged Sediments as Affected by Cxidation-Reduction Potential and pH. Vol. II: Materials and Methods, Results and Discussion. U.S. Army Engineer Waterways Experiment Station, Contract Rep.D77-4, CE, Vicksburg, Miss.

Haines, T.A. 1986. Fish Population Trends in Response to Surface Water Acidification, chapter 8, pp: 300-334. In: Acid Deposition Long-Term Trends, National Research Council. Washington, DC: National Academy Press. 
Hakanson, L., A. Nilsson, and T. Andersson. 1988. Mercury in fish in Swedish lakes. Environmental Pollution49: 145-162.

Hem, J.D. 1972. Chemistry and occurrences of cadmium and zinc in surface water and groundwater. Water Resources Research 8: 661-679.

Henkens, Ch.H. 1983. Cadmium in meststoffen. Bedrijfsontwikkeling 14: 484.

Hunt, C.D. and D.L. Smith. 1983. Remobilization of metals from polluted marine sediments. Canadian Journal of Fisheries and Aquatic Science 40(Suppl. 2): 132-142.

Husar, R.B. 1986. Emissions of Sulfur Dioxide and Nitrogen Oxides and Trends for Eastern North America, chapter 2, pp: 48-92. In: Acid Deposition Long-Term Trends, National Research Council. Washington, DC: National Academy Press.

Huygen, C. and F.W. van Ijssel. 1981. Luchtverontreiniging bij kassen door bodemontsmetting met methylbromide. IMG-TNO, Delft, Report no. G 1048.

IB, 1987a. Dutch Institute for Soil Fertility, Haren. Reported in Environmental Statistics of The Netherlands 1987, p. 64. Netherlands Central Bureau of Statistics, Department of Environmental Statistics, The Hague.

IB, 1987b. Dutch Institute for Soil Fertility, Haren. Reported in Environmental Statistics of The Netherlands 1987, p. 63. Netherlands Central Bureau of Statistics, Department of Environmental Statistics, The Hague.

IIASA. 1988. IIASA's Acid Rain Project has estimated $\mathrm{SO}_{2}$ emissions for West Germany, Switzerland, Austria, and Czechoslovakia for the years 1975, 1980, and 1985, based or the Official Energy Pathways reported by the respective countries. Total emissions in 1975 were 6,545 kilotons. Between 1975 and 1980 total emissions increased by about $4 \%$. However, between 1980 and 1985 emissions decreased by about $6 \%$. Overall, between 1975 and 1985 , emissions decreased by about $2 \%$.

Jansson, M., L. Leonardsson, and U. Rönner. 1986. Denitrification in rivers draining arable land decreases the nitrogen loading in Swedish coastal waters. Vatten 42:25 32.

John, M.K. 1972. Uptake of soil-applied cadmium and its distribution in radishes. Canadian Journal of Plant Science 52: 715-719.

John, M.K., C.J. Van Laerhoven, and H.H. Chuah. 1972. Factors affecting plant uptake and phytotoxicity of cadmium added to soils. Environmental Science and Technology 6:1005 - 1009 .

Kersten, M., and U. Foerstner. 1987. Cadmium Associations in Freshwater and Marine Sediments. In: Cadmium in the Aquatic Environment, J.O. Nriagu and J.B. Sprague (eds.). New York: John Wiley \& Sons.

Khalid, R.A. 1980. Chemical Mobility of Cadmium in Sediment- Water Systems, chapter 8, pp: 257-304. In: Cadmium in the Environment, J.O. Nriagu (ed.). New York: John Wiley \& Sons.

Lu, J.C.S. and K.Y. Chen. 1977. Migration of trace metals in interfaces of seawater and polluted surficial sediments. Environmental Science and Technology 11: 174-182.

MacLean, A.J. 1976. Cadmium in different plant species and its availability in soils as influenced by organic matter and additions of lime, P, Cd and $\mathrm{Zn}$. Canadian Journal of Soil Science 56: 129-138.

Manabe, S. and T. Wetherald. 1986. Reduction in summer soil wetness induced by an increase in atmospheric carbon dioxide. Science 232: 626-628.

Miljostyrelsen. 1984. Oxygen depletion and fish kill in 1981-- extent and causes (in Danish). (Miljostyrelsen $=$ The National Agency of Environmental Protection Denmark.)

Miller, J.E., J.J. Hassett, and D.E. Koeppe. 1976. Uptake of cadmium by soybeans as influenced by soil cation exchange capacity, $\mathrm{pH}$, and available phosphorus. Journal of Environmental Quality 5: 157-160. 
Mooney, H.A., P.M. Vitousek, and P.A. Matson. 1987. Exchange of materials between terrestrial ecosystems and the atmosphere. Science 238:926 - 932.

National Research Council (NRC). 1985. Acid Deposition Effects on Geochemical Cycling and Biological Availability of Trace Elements. Washington, DC: National Academy Press.

National Research Council (NRC). 1984. Acid Deposition: Processes of Lake Acidification. Washington, DC: National Academy Press.

OECD. 1985. The State of the Environment 1985. Organization for Economic Cooperation and Development, Paris.

Olsthoorn, A.A. and R. Thomas. 1986. Milieuverontreiniging door cadmuim 1981-200. Amsterdam: Instituut voor Milieuvraagstukken, Vrije Universiteit.

Paces, T. 1985. Acidification in Central Europe and Scandinavia: a competition between anthropogenic, geochemical and biochemical processes. Ambio 14: 354-356.

Parry, M. and T. Carter. 1987. The Assessment of Effects of Climatic Variations on Agriculture: Aims, Methods and Summary of Results. In: The Impact of Climatic Variations on Agriculture. Volume 1. Assessments in Cool Temperate and Cold Regions, M.L. Parry, T.R. Carter, and N.T. Konijn (eds.). Dordrecht, the Netherlands: Reidel.

Pinay, G. and H. DeCamps. 1988 (in press). The role of riparian woods in regulating nitrogen fluxes between the alluvial aquifer and surface water: a conceptual model. Regulated Rivers, September 1988.

Prause, B., E. Rehm, and M. Schulz-Baldes. 1985. The remobilization of $\mathrm{Pb}$ and Cd from contaminated dredge spoil after dumping in the marine environment. Environmental Technology Letters 6: 261-266.

Renberg, I. 1986. In: Diatoms and Lake A cidity, pp: 213-219, J.P. Smol, R.W. Battarbee, R.B. Davis, and J. Merilainsen (eds.). Dordrecht, The Netherlands: Junk.

Rippon, J.E., R.A. Skeffington, M.J. Wood, K.A. Brown and D.J.A. Brown. 1980. Hydrogen, Sulphur, and Nitrogen Budgets in Soils and Catchments, pp.276 - 277. In: Ecological Impacts of Acid Precipitation, D. Drablos and A. Tollan (eds.). SNSF Project, Oslo, Norway.

Salomons, W. 1983. Trace metals in the Rhine, their past and present (1920 - 1983) influence on aquatic and terrestrial ecosystems. In: Proc. Intern. Conf. Heavy Metals in the Environment, Heidelberg, pp. 764 - 771. CEP - Consultants, Edinburgh.

Salomons, W. and J.A. Van Pagee. 1981. Biogeochemical processes affecting metal concentrations in lake sediments (IJsselmeer, The Netherlands). Science Total Environment 16:217 - 229.

Sauerbeck, D. 1987. Effects of Agricultural Practices on the Physical, Chemical and Biological Properties of Soils: Part II--Use of Sewage Sludge and Agricultural Wastes, pp: 181-210. In: Scientific Basis for Soil Protection in the European Community, H. Barth and P.L. L'Hermite (eds.). London: Elsevier Applied Science.

Schoumans, O.F., A. Breeuwsma, and H. de Vries. 1987. Use of soil survey information for assessing the phosphate sorption capacity of heavily manured soils, pp: 10791088. In: Vulnerability of Soils and Groundwater to Pollutants; International Conference, Noordwijk aan Zee, The Netherlands, March 30 - April 3, 1987. The Hague: National Institute of Public Health and Environmental Hygiene.

Schroder, H. 1985. Nitrogen losses from Danish agriculture-- trends and consequences. Agriculture, Ecosystems and Environment 14: 279-289.

Stevenson, F.J. 1972. Organic matter reactions involving herbicides in soils. Jcurnal of Environmental Quality 1: 333.

Tamm, C.O. and L. Hallbaecken. 1988. Changes in soil acidity in two forest areas with different acid deposition: 1920 s to 1980 s. A mbio 17: 56-61. 
Tyler, G., D. Berggren, B. Bergkvist, U. Falkengren-Grerup, L. Folkeson, and A. Ruehling. 1985. Soil acidification and metal solubility on forests of south Sweden. The NATO Advanced Research Institute Workshop: Effects of air pollutants, especially acidic deposition on forests, agriculture and wetlands; Toronto, May 12-17, 1985.

Vitt, D.H. and S. Bayley. 1984. The vegetation and water chemistry of four oligotrophic basin mires in northwestern Ontario. Canadian Journal of Botany 62:1485 - 1500.

VROM, 1980. Dutch Ministry of Housing, Physical Planning and Environment, Leidschendam. Reported in Environmental Statistics of The Netherlands 1987, pp. 68-69. Netherlands Central Bureau of Statistics, Department of Environmental Statistics, The Hague.

V \& W, 1987. Dutch Ministry of Transport and Public Works, The Hague. Reported in Environmental Statistics of The Netherlands 1987, pp. 50, 57. Netherlands Central Bureau of Statistics, Department of Environmental Statistics, The Hague.

Wallace, A., E.M. Romney, G.V. Alexander, S.M. Soufi, and P.M. Patel. 1977. Some interactions in plants among cadmium, other heavy metals, and chelating agents. Agronomy Journal, 69: 18-20.

Wieder, R.K. and G.E. Lang. 1984. Influence of wetlands and coal mining on stream water chemistry. Water, Air, and Soil Pollution 23: 381 - 396.

Williams, C.H., and D.J. David. 1976. The accumulation in soil of cadmium residues from phosphate fertilizers and their effect on the cadmium content of plants. Soil Science 121: 86-93.

Williams, C.H. and D.J. David. 1973. The effect of superphosphate on the cadmium content of soils and plants. Australian Journal of Soil Research 11: 43-56.

WL, 1987. Delft Hydraulics, Delft. Reported in Environmental Statistics of The Netherlands 1987, p. 64. Netherlands Central Bureau of Statistics, Department of Environmental Statistics, The Hague.

Wollast, R. 1983. Interactions in Estuaries and Coastal Waters, chapter 14, pp: 385-410. In: The Major Biogeochemical Cycles and Their Interactions, SCOPE 21, B. Bolin and R.B. Cook (eds.). New York: John Wiley \& Sons.

Wood, J.M. 1980. The Role of $\mathrm{pH}$ and Oxidation-Reduction Potentials in the Mobilization of Heavy Metals. In: Polluted Rain, M.W. Miller, and P.E. Morrow (eds.). New York: Plenum Publishing Corp. 
